\title{
CUATRO MILLONES DE POBRES EN CHILE: ACTUALIZANDO LA LÍNEA DE POBREZA*
}

\author{
Felipe Larraín Bascuñán
}

Para medir la pobreza, en Chile se aplica el método de la Canasta de Satisfacción de Necesidades Básicas. Su base es una canasta mínima de alimentación y un factor multiplicador que entrega el costo total de satisfacer las necesidades mínimas alimentarias y no alimentarias. El valor resultante se compara con el ingreso familiar. De acuerdo a las cifras oficiales, la pobreza se habría reducido del 18,7\% de la población en 2003 al 13,7\% en 2006. Sin embargo, la canasta actualmente vigente se elaboró en base a los patrones de consumo de los hogares del Gran Santiago en los años 1987-1988, en circunstancias que desde entonces han ocurrido muchos cambios económicos, demográficos y sociales que hacen necesaria una actualización de la línea de pobreza. Para ello, se cuenta actualmente con la información de la V Encuesta de Presupuestos Familiares, realizada entre 1996 y 1997, la que ya fue usada hace años para actualizar la canasta del IPC.

Este trabajo hace uso del análisis desarrollado por la Fundación para la Superación de la Pobreza para actualizar la línea de pobreza de acuer-

FeliPe LaRraín. Ingeniero Comercial, Universidad Católica de Chile. MA y Ph.D. en Economía, Universidad de Harvard. Profesor Titular del Instituto de Economía de la Universidad Católica de Chile. Director de la Fundación para la Superación de la Pobreza. Entre 1977 y 1999 fue Profesor Titular Visitante de la Cátedra Robert F. Kennedy de Estudios Latinoamericanos en la Universidad de Harvard.

* Me he beneficiado de los muy valiosos comentarios de la Fundación para la Superación de la Pobreza, en particular los de Leonardo Moreno, Mauricio Rosenbluth y Rodrigo Jordán, y los de José Díaz, Francisco Gallego y Salvador Valdés, así como de la eficiente asistencia de investigación de Juan Bravo y Fernando Luco.

Estudios Públicos, 109 (verano 2008). 
do a la información oficial disponible. En base a ello, este artículo rehace los cálculos y determina que la pobreza afectaba todavía al 29\% de la población en 2006, es decir, más del doble de la cifra oficial. En el desarrollo de la argumentación se exponen detalladamente los distintos conceptos de pobreza, las razones por las que es necesario realizar esta actualización, y los desafíos pendientes.

\section{INTRODUCCIÓN}

$P_{\text {art }}$ importancia, y muchas de las políticas sociales y económicas apuntan sus esfuerzos a combatirla. La razón de esto es evidente: la pobreza limita seriamente la vida de quienes la sufren, y aunque sus efectos recaen principalmente sobre las personas afectadas, es un mal para la población en general, por lo que debiera ser considerada una realidad inaceptable en cualquier sociedad. En este sentido, la medición de la pobreza se vuelve una herramienta de suma relevancia para evaluar el desarrollo social alcanzado por un país, al permitir dimensionar la magnitud del problema que sufre una parte importante de la población que no logra las condiciones mínimas necesarias para vivir con dignidad y hacer uso efectivo de su libertad. Es por ello que gobiernos, instituciones académicas y organizaciones locales e internacionales dedican importantes recursos a medir la pobreza. Los resultados de estas mediciones sirven de base para tomar importantes decisiones de política, en particular la implementación de planes y programas sociales.

Sin embargo, el concepto de pobreza no es, por su naturaleza, algo que todos perciban de una única forma, por lo que debe ser planteado dentro de un contexto conceptual que contenga juicios respecto a la naturaleza de las carencias que experimenta el ser humano y la importancia de éstas. Dado que estos juicios se fundan en elementos filosóficos, es inevitable la existencia de múltiples conceptos de pobreza, por lo que también existen diversas maneras de cuantificarla. En Chile, la pobreza se mide cotejando el ingreso familiar con el costo de una Canasta de Satisfacción de Necesidades Básicas (CSNB) que contiene un grupo de bienes y servicios valorados a precios de mercado. De aquí surgen, como se explica en este trabajo, la Línea de Pobreza y la Línea de Indigencia.

La canasta oficial actual utiliza como base la IV Encuesta de Presupuestos Familiares (IV EPF) que hizo el Instituto Nacional de Estadísticas (INE) en 1987-1988. Ésta aportó información sobre el consumo de las familias en el Gran Santiago; por ende, durante estas dos décadas la canasta 
oficial nunca se ha basado en datos de carácter nacional. Sin embargo, durante los últimos veinte años el país ha experimentado cambios importantes en su nivel de ingreso, empleo, en el rango de productos disponibles (las rebajas arancelarias, por ejemplo, han permitido un mayor acceso a bienes importados) y en el acceso al crédito. También han ocurrido cambios demográficos y sociales importantes, tales como la caída en las tasas de fertilidad de la población y el creciente grado de urbanización. No obstante, ninguno de estos cambios ha sido internalizado en la CSNB. Esto resulta sorprendente, ya que otros instrumentos, como la Ficha CAS (que fue descontinuada, creando en su lugar la Ficha de Protección Social, la que se utiliza para asignar subsidios y otros beneficios), la canasta del IPC (que se elabora con la misma EPF) y las cuentas nacionales, han sido reformulados y/o actualizados en consideración a las profundas transformaciones experimentadas en el país al menos una vez durante las últimas dos décadas.

Las consideraciones anteriores cuestionan a la actual CSNB oficial en su confiabilidad para determinar quiénes son pobres y quiénes no lo son. Resulta evidente que esta CSNB ha perdido validez, porque representa los patrones de consumo que prevalecían hace 20 años, en circunstancias, que ha habido profundos cambios desde esa época. Estos han provocado transformaciones tanto en las necesidades de las personas como en las formas de satisfacerlas.

Dado que se dispone desde hace más de ocho años de la información de la V Encuesta de Presupuestos Familiares (V EPF), que realizó el INE entre los años 1996 y 1997, resulta inexplicable no actualizar la canasta. Esto es sumamente relevante, puesto que la utilización de un instrumento obsoleto genera cifras de pobreza que son alejadas de la realidad. En este caso, el uso de la IV EPF arroja un panorama excesivamente optimista de la situación de pobreza en Chile, y, por ende, genera la sensación de que el problema es mucho menor de lo que realmente es. Esto afecta la prioridad del combate a la pobreza en el debate público y el diseño de las políticas públicas para atacarla, perjudicando directamente a los pobres.

Este trabajo pretende aportar al debate de la actualización y perfeccionamiento del indicador de pobreza para Chile. La presente propuesta busca contribuir a la determinación de líneas de pobreza e indigencia que reflejen adecuadamente el costo de los satisfactores básicos que actualmente privilegian las familias y que están disponibles en el mercado en cantidad suficiente. La nueva CSNB que surge de este análisis utiliza la última encuesta de presupuestos familiares disponible (V EPF de 1996-1997) y recoge el trabajo técnico desarrollado por la Fundación para la Superación de la Pobreza (FSP). 
El trabajo se organiza como sigue. La sección 2 muestra los múltiples significados asociados al fenómeno de la pobreza, así como los diferentes métodos que se han utilizado en Chile para su medición, los elementos necesarios para construir estas medidas y las cifras obtenidas. La sección 3 introduce el debate respecto a la medición de la línea de pobreza; ahí se discuten los argumentos por los que resulta imprescindible actualizar la canasta, así como sus obstáculos y consecuencias, y las experiencias de algunos países al respecto. La sección 4 desarrolla la metodología para actualizar la CSNB en Chile y define en base a ella una canasta actualizada. A continuación, la sección 5 determina nuevas líneas de pobreza, presentando cifras para 2000, 2003 y 2006 basadas en esta actualización. Por último, la sección 6 concluye con una discusión de las limitaciones del trabajo, así como los desafíos metodológicos pendientes.

\section{2. ¿CÓMO SE MIDE LA POBREZA?}

Uno de los propósitos fundamentales de este trabajo es determinar de una manera más precisa la pobreza en nuestro país. En particular, nos preguntaremos respecto a la manera más adecuada de medir la pobreza. Sin embargo, para poder analizarla, se requiere antes definir la pobreza.

\section{1. ¿Qué entendemos por pobreza?}

No existe una definición única y universal de la pobreza. En la realidad, no hay una forma única de pobreza, sino que diferentes formas en que este fenómeno se presenta. Pese a lo anterior, un elemento común a todas las definiciones es la privación de los elementos necesarios para la vida humana dentro de la sociedad. En efecto, según la Real Academia Española la definición de pobre es "Necesitado, que no tiene lo necesario para vivir".

El Programa de las Naciones Unidas para el Desarrollo (PNUD, 1997) define la pobreza como la incapacidad de las personas de vivir de una manera tolerable. De acuerdo a esta institución, el concepto se refiere a la falta de oportunidad de vivir una vida larga, sana y creativa y disfrutar de un nivel decente de vida, libertad, dignidad, respeto por sí mismo y de los demás.

Por otro lado, la CEPAL definió inicialmente la pobreza como un "síndrome situacional en el que se asocian el infraconsumo, la desnutrición, las precarias condiciones de vivienda, los bajos niveles educacionales, las malas condiciones sanitarias, una inserción inestable en el aparato producti- 
vo, actitudes de desaliento y anomia, poca participación en los mecanismos de integración social y quizá la adscripción a una escala particular de valores, diferenciada en alguna medida de la del resto de la sociedad" (Altimir, 1979). Más tarde, se incorporaron otros elementos a la definición, refiriéndose a la pobreza como "el resultado de un proceso social y económico — con componentes culturales y políticos- en el cual las personas y los hogares se encuentran privados de activos y oportunidades esenciales por diferentes causas y procesos, tanto de carácter individual como colectivo, lo que le otorga un carácter multidimensional” (CEPAL, 2003).

De acuerdo al Banco Mundial (2001), el concepto de pobreza incluye elementos como la falta de acceso a libertades fundamentales de acción y decisión, la carencia de viviendas, alimentos y de servicios de educación y salud adecuados, que se traducen en ser más vulnerables a las enfermedades, los reveses económicos y los desastres naturales.

Las definiciones anteriores nos muestran a la pobreza como un fenómeno de carácter multidimensional, que engloba aspectos tangibles e intangibles. Sin embargo, es evidente que muchos puntos de las definiciones presentan dificultades técnicas importantes para medirlos. Así, mientras elementos como la carencia de una nutrición adecuada o el logro de un cierto nivel de consumo son relativamente fáciles de observar y cuantificar, no ocurre lo mismo cuando se habla de elementos ligados a la calidad de vida o la sensación de desaliento que provoca estar en pobreza.

Por ello, la gran mayoría de los estudios económicos sobre pobreza se han restringido a medir los aspectos que resultan más fáciles de cuantificar, que son, generalmente, los elementos materiales. Es decir, en la práctica las mediciones se concentran en los aspectos tangibles. Aun así, esta tarea resulta bastante compleja. La siguiente sección trata justamente de la manera de realizar estas mediciones.

\subsection{La medición de la pobreza}

Una vez establecidos los aspectos que abarca el concepto de pobreza, se requiere de indicadores capaces de cuantificar lo que queremos medir, y que guarden relación con la definición elegida. Los métodos de medición de la pobreza, en general no calzan de manera unívoca con una definición en especial. Sin embargo, los más usados guardan una relación preferente con algunas de ellas.

Como una forma de organizar la discusión respecto a los métodos de medición, resulta útil realizar una clasificación de éstos. Los enfoques para medir la pobreza pueden clasificarse de tres maneras: 
- $\quad$ Objetivos-Subjetivos

- Absolutos-Relativos

- Directos-Indirectos.

Cabe destacar que estas tres categorías no son excluyentes entre sí, puesto que clasifican a los métodos según criterios distintos. Así, por ejemplo, el método de la Canasta de Satisfacción de Necesidades Básicas, que es el de mayor interés en este trabajo, puede clasificarse como un enfoque objetivo, absoluto e indirecto. A continuación se exponen los diversos enfoques de medición de la pobreza.

\section{Enfoque objetivo}

Este tipo de enfoques han sido los más utilizados en la medición de la pobreza. Definen la pobreza a partir de un conjunto de juicios normativos, determinando los requisitos para dejar de ser pobre. Se basan en mediciones de carácter cuantitativo, resumidas a través de indicadores monetarios o no monetarios, que son externos y únicos para todos los individuos y hogares. En este sentido, las mediciones se fundan en los criterios y normas de especialistas, dando como resultado las condiciones reales de privación que sufre el individuo, independiente de la percepción y/o sentimientos que éstos tengan sobre su situación. En lo posible, estos indicadores deben estar lo más estrechamente ligados con el bienestar de los individuos, de modo que sean aceptados por la sociedad.

Entre sus ventajas se cuentan la transparencia de sus fundamentos, la mayor facilidad de comparar sus mediciones (al ser de carácter cuantitativo) y el hecho de que su desagregación entre grupos de la población identificados por características observables resulta más fácil, permitiendo así el diseño de programas dirigidos a grupos prioritarios y una mejor comprensión de los determinantes de la pobreza.

\section{Enfoque subjetivo}

Los críticos de los enfoques objetivos señalan que su gran problema es que la medición es afectada de una manera arbitraria por el investigador, ya que éste realiza juicios de valor respecto al nivel del ingreso que determina la línea de pobreza o la canasta que satisface los requerimientos nutricionales mínimos. En cambio, el enfoque subjetivo considera que, por su esencia, las necesidades básicas tienen un componente subjetivo, por lo que las 
líneas de pobreza deben obtenerse a partir del juicio que las personas tienen sobre los bienes y servicios que consideran esenciales (y del ingreso mínimo necesario para obtenerlos), y no por el de la persona que realiza el estudio. En este sentido, el individuo "es el mejor juez de su propia situación”.

Cuando se usa este enfoque, se busca, entre otras cosas, que las personas expresen si se consideran pobres, y que comenten respecto a las condiciones de vida que les ofrece su hogar. Toda esta información se cuantifica en términos monetarios para determinar el valor de una línea de pobreza, o alternativamente, se utiliza en un contexto no monetario, como ocurre con las líneas o índices de privación utilizados en el Reino Unido e Irlanda, en que la población opina sobre las necesidades que todo hogar o persona debiera satisfacer, considerando pobres a aquellos que no lo logran.

Los indicadores subjetivos permiten evaluar con mayor profundidad la situación de una unidad familiar en particular, así como definir o justificar la elección de líneas de pobreza, las que además facilitan incorporar el tamaño familiar y obtener así escalas de equivalencia. También permiten una mejor visualización respecto a economías de escala y diferencias regionales en el costo de la vida. Estos indicadores además resultan útiles para complementar a los indicadores objetivos, puesto que permiten conocer la sensación de la gente respecto a su propia situación y entender mejor las características de la pobreza.

Existen varias desventajas de este enfoque. En primer lugar, los indicadores autopercibidos pueden verse distorsionados por las expectativas de los individuos, llegando a reproducir los patrones de discriminación o marginación presentes en la sociedad. Además, las estimaciones pueden generar errores considerables si la muestra es pequeña, mientras que la varianza de las respuestas resulta demasiado alta si la muestra es grande, lo que hace difícil construir una línea de pobreza con intervalos de confianza razonables. Por otro lado, algunos de los encuestados (aquellos que sufren mayores carencias) pueden modificar sus respuestas si creen que la línea de pobreza resultante determinará la asistencia social a obtener. Finalmente, en este enfoque no desaparecen las elecciones arbitrarias, puesto que el fraseo de las preguntas realizadas a la población puede inducir sus respuestas.

\section{Enfoque absoluto}

Los países en desarrollo han optado preferentemente por un enfoque de tipo absoluto, que considera un núcleo de necesidades humanas 
elementales que deben ser satisfechas para no ser considerado pobre. Por tanto, este enfoque requiere encontrar valores universales que permitan dirimir quiénes son pobres. Cuenta con una gran variedad de métodos alternativos, incluyendo los de tipo directo, como el de Necesidades Básicas Insatisfechas, e indirectos, como el de la Canasta de Satisfacción de Necesidades Básicas, los que se discuten más adelante.

Una ventaja de este enfoque es obtener mediciones comparables en el tiempo, permitiendo la evaluación de la efectividad de las políticas sociales. Además, permite poner el acento en aquellas situaciones donde no se cumplen los requisitos mínimos para la supervivencia física, como ocurre hoy en muchos países en desarrollo. Sin embargo, una desventaja es que puede dificultar la identificación de los que siguen siendo pobres en una sociedad que progresa y va satisfaciendo sus necesidades más elementales; esto ocurre, por ejemplo, con la variante de 1 dólar a PPA que se discute más adelante.

\section{Enfoque relativo}

De acuerdo a este enfoque las necesidades surgen de la comparación con el resto de la sociedad, por ello, las líneas de pobreza que emanan de aquí se fijan en relación al ingreso medio de un país. Esta noción de pobreza debe entenderse, entonces, como una situación de privación relativa respecto al grupo social de referencia, y como consecuencia ésta se actualiza toda vez que se observen cambios en el ingreso total y su distribución. Es un enfoque que ha comenzado a adoptarse en sociedades desarrolladas. De acuerdo a Sen (1984), este método se originó a mediados del siglo pasado, en respuesta al fracaso de los estudios de pobreza basados en líneas de pobreza absoluta, que no reflejaban las cambiantes necesidades de las personas a lo largo del tiempo.

Entre sus ventajas, permite monitorear los sectores que están rezagados respecto al resto de la sociedad en países en donde todos los habitantes ya satisfacen las condiciones mínimas necesarias para la existencia humana. Además, no se requiere la especificación y construcción de instrumentos que deban ser actualizados periódicamente. Se le ha criticado, en cambio, por relacionar directamente desigualdad con pobreza, fenómenos que - aunque relacionados - son diferentes, y por la arbitrariedad en la elección del porcentaje de ingresos para determinar la línea de pobreza, al no guardar relación con criterios explícitos respecto a necesidades humanas básicas. Otra crítica es que con este método resulta prácticamente imposible evaluar la efectividad de las políticas en el tiempo. 


\section{Enfoque directo}

Bajo este enfoque se observan directamente las condiciones de vida de la población, y la condición de pobreza depende de cuán alejadas estén ellas de los estándares sociales. Así, en vez de medir la posibilidad de realizar consumo (característica del enfoque indirecto), aquí se mide el consumo efectivamente realizado. A continuación se presentan algunos de los métodos agrupados bajo este enfoque.

\section{Método de Necesidades Básicas Insatisfechas (NBI)}

Este método fue uno de los más difundidos en América Latina durante los ochenta, pero perdió terreno durante los noventa. Hoy es una medición considerada de carácter complementario. Se basa en una definición de pobreza asociada a "necesidad”. Por ser un método directo, lo que importa para el bienestar es que las necesidades básicas preestablecidas hayan sido efectivamente cubiertas y no si se posee el ingreso propio para satisfacerlas.

Usando información censal, se verifica si los hogares satisfacen un conjunto de necesidades establecidas previamente, siendo las más comunes en este tipo de estudios aquellas relacionadas con abastecimiento de agua, materialidad de la vivienda, servicios sanitarios, hacinamiento crítico, disponibilidad de energía, inasistencia escolar, entre otros.

La decisión definitiva de las variables a incluir se funda en criterios técnicos y en la información disponible. Una vez establecidas las variables respectivas, se debe establecer el umbral de privación que determinará a quienes se considera pobres, en términos de estas carencias. En general, cuando un hogar presenta alguna carencia, se considera pobre por NBI, y si presenta dos o más, se considera en situación de miseria por NBI.

Una ventaja de este método es que permite la elaboración de mapas de pobreza, lo que posibilita la identificación de las zonas que requieren prioridad al momento de diseñar programas sociales con un elevado nivel de desagregación geográfica, facilitando la focalización del gasto. Sin embargo, la gran limitación del método es que sólo permite conocer cuántos hogares no han satisfecho alguna de las necesidades básicas estipuladas, pero es de dudosa utilidad para medir la pobreza, puesto que no es posible relacionar la condición de pobreza con una determinada cantidad de NBI en forma única y establecida. Esto puede dar pie a la arbitrariedad del investigador, quedando completamente a su criterio la clasificación de quienes están en pobreza. De este modo, en una misma situación se pueden obtener 
mediciones diferentes de pobreza cuando hay desacuerdo respecto a las necesidades consideradas como básicas, los indicadores que miden esas necesidades o los criterios para establecer carencias, entre otros. Por otro lado, es difícil trabajar con índices que agrupan variables de naturaleza muy diferente, y que por lo mismo son difíciles de comparar y jerarquizar.

\section{Índice de Pobreza Humana (IPH)}

Este índice es una extensión del Índice de Desarrollo Humano surgido del PNUD en 1997, que se concentra específicamente en la pobreza. El IPH define elementos básicos para el desarrollo humano, sin los cuales el individuo se clasifica como pobre. En particular, toma en cuenta tres dimensiones de pobreza:

- $\quad$ Supervivencia: porcentaje de personas que no sobrevivirá hasta los 40 años

- $\quad$ Conocimiento: porcentaje de adultos analfabetos

- $\quad$ Nivel de vida: promedio simple entre el porcentaje de personas sin acceso a agua potable, el porcentaje de personas sin acceso a servicios de salud y el porcentaje de niños menores de 5 años con peso insuficiente.

En 1998, el índice se dividió en dos variantes, denominándose IPH-1 al indicador aplicado a los países en desarrollo y IPH-2 al de los países industrializados. El IPH-2 agrega características como la exclusión, medida por la tasa de desempleo, y el porcentaje de la población que vive con un ingreso inferior al 50\% del promedio (es decir, se considera el concepto de pobreza del enfoque relativo). Nótese que en este método persisten aspectos relativos (personas con ingreso inferior al 50\% del promedio), aunque la gran mayoría de sus características permiten clasificarlo como "directo".

Entre sus ventajas se puede mencionar que es fácil de calcular, comunicar y extender, por lo que ha recibido gran atención en la literatura económica. Por otro lado, aunque se distingue del método de NBI por la selección de las variables asociadas a la pobreza, así como a las ponderaciones asociadas a éstas, el método de identificación de pobreza es esencialmente el mismo, por lo que básicamente comparte sus limitaciones.

\section{Enfoque indirecto}

Este enfoque clasifica como pobres a aquellos individuos que no cuentan con los ingresos suficientes que les permitan satisfacer sus necesi- 
dades básicas, es decir, se evalúa la capacidad de realizar consumo. El enfoque indirecto utiliza "líneas de pobreza", que establecen el ingreso o el gasto mínimo necesario para mantener un nivel de vida adecuado, de acuerdo a determinados estándares. Por ende, son pobres aquellos que no alcanzan el valor determinado por la línea. A continuación se presentan algunos de los métodos usados en este enfoque.

\section{Consumo calórico}

De acuerdo a este método, la línea de pobreza se determina por el nivel de ingreso o gasto que permite al individuo obtener un determinado consumo de calorías. La cantidad de calorías necesarias se obtiene de estudios nutricionales, bajo ciertos supuestos respecto al nivel de actividad física.

El cálculo de la línea de pobreza se ha realizado básicamente de dos maneras. Una opción es seleccionar una submuestra de hogares con un consumo calórico cercano al requerido, considerando su ingreso promedio como la línea de pobreza. La otra manera es estimar una regresión entre consumo calórico e ingreso, y usarla para obtener el ingreso necesario para consumir las calorías establecidas como necesarias.

Las ventajas de este método respecto de otros son los menores requerimientos de información y el hecho de que no se necesita fijar un componente no alimentario para determinar la línea de pobreza. Su gran limitación es que la relación entre gasto y consumo energético varía según los gustos, niveles de actividad física, precios relativos, etc., variaciones que no necesariamente implican un cambio de bienestar. Además, está basado en la satisfacción de una sola necesidad, lo que resulta demasiado simplista.

Método de la Canasta de Satisfacción de Necesidades Básicas (CSNB)

Este método es uno de los más difundidos en América Latina. Al igual que el anterior, es de tipo indirecto ya que no ausculta el consumo efectivo de los hogares, sino que analiza su capacidad de consumo a partir de sus ingresos. Puede considerarse una extensión del anterior, ya que en vez de basarse en la satisfacción de una necesidad única (alimentación), la construcción de la canasta básica de consumo incorpora varios bienes y servicios considerados esenciales. 
La canasta de bienes y servicios básicos se elabora en base a las recomendaciones de expertos y los patrones de consumo observados en la población. Luego, se determina su costo en base a los precios de mercado prevalecientes, lo que permite establecer el ingreso mínimo necesario para adquirir esa canasta. Pobres son aquellos hogares cuyo ingreso es inferior a este nivel. Indigentes son aquellos cuyo ingreso ni siquiera les permite satisfacer sus necesidades alimentarias.

Una importante virtud de este método es su simplicidad, que facilita su comprensión y discusión. Además, permite evaluar el éxito de las políticas para combatir la pobreza en el tiempo. Entre sus limitaciones está el incorporar juicios de valor, como los relacionados con la elección de los alimentos que satisfacen las necesidades nutricionales y la fijación de calidades y precios para estos. Por otro lado, si bien existen criterios claros respecto a la determinación de la canasta básica de alimentos, la estimación de las otras necesidades constituye un elemento de amplio desacuerdo debido a que resulta mucho más arbitrario, y, según cómo se calcule, esconde en mayor o menor medida el verdadero costo de satisfacer estas necesidades, además de ignorar las necesidades satisfechas gracias a la provisión de bienes y servicios públicos (véase, por ejemplo, Feres, 1997). Este trabajo toma como base este método e intenta avanzar en la superación de algunas de estas limitaciones, lo que se realiza en las siguientes secciones.

\section{Un dólar diario a paridad de poder adquisitivo (PPA)}

La línea de pobreza de un dólar diario fue adoptada por el Banco Mundial en 1990 y corresponde al costo de una canasta básica de alimentos en varios de los países más pobres de Asia y África. Con el objeto de facilitar las comparaciones internacionales, el valor de la canasta es ajustado por paridad de poder adquisitivo (PPA). Esto se hace para corregir diferencias de poder adquisitivo de un dólar en distintos países. Por ejemplo, un dólar tiene mayor poder de compra en India o Haití que en Inglaterra o Suiza; dichas diferencias son “corregidas” al utilizar el dólar a PPA. De acuerdo al Banco Mundial se clasifican como extremadamente pobres todas aquellas personas que disponen de menos de un dólar diario a PPA.

Este método ha recibido varias críticas. En primer lugar, no posee un adecuado sustento conceptual ni se basa en ningún parámetro de consumo mínimo reconocible, por lo que no recoge de manera realista las necesidades que deben ser cubiertas para sobrevivir; por ello, algunos autores sugieren elevar la línea de pobreza por lo menos al doble. La corrección por PPA 
también ha sido cuestionada, ya que el ajuste se hace en base a una canasta de bienes que recoge el consumo medio internacional de diversos bienes, aumentando el peso de los servicios frente a los bienes básicos como los alimentos. Así, la canasta internacional muestra un patrón de consumo más sesgado hacia los prevalecientes en los países desarrollados.

El mismo Banco Mundial ha advertido que se debe actuar con cautela al realizar comparaciones internacionales con esta medición, sugiriendo que la línea de pobreza de US\$1, que es normalmente usada en África y el Sudeste Asiático, debiera ser cambiada por una línea de US\$2 diarios por persona en América Latina, aproximadamente de US\$4 en Europa del Este y Asia Central y una de US\$0.60 en China (Banco Mundial, 1996).

\section{Aplicación de los métodos: importancia del contexto}

Como hemos visto, la medición de pobreza puede realizarse por diversos métodos, que difieren conceptualmente. Dado que todos los enfoques tienen defectos y virtudes, la teoría no permite una opción única. Es la experiencia y el contexto de cada país los que definen la aplicación de un determinado método. Los métodos absolutos han sido más populares en los países en desarrollo, ya que el núcleo que aún no logra cumplir con las necesidades mínimas sigue siendo importante, en tanto, los métodos relativos y subjetivos lo han sido en países desarrollados. En los países en desarrollo, la privación relativa no resulta tan importante como la imposibilidad de satisfacer las necesidades mínimas, por lo que en estos países se ha optado por el método de necesidades básicas insatisfechas y/o el costo de la canasta de satisfacción de necesidades básicas. Existen excepciones, como la línea de pobreza absoluta para Estados Unidos basada en el trabajo de Orshansky (1963). También existen líneas de pobreza relativa para países en desarrollo; Pradhan y Ravallion (1997) aplican este método a Jamaica y Nepal, y concluyen que las medidas de pobreza subjetiva están muy cerca de las absolutas. También existe una medición relativa realizada por CEPAL (2007) tanto para América Latina en conjunto como individualmente para 17 países de la región, aunque en este caso los resultados de pobreza relativa no coinciden mayormente con los arrojados a través de la medición de pobreza absoluta, cambiando fuertemente el ordenamiento en el ranking de los países.

Con todo, los diversos enfoques, más que verse como sustitutos, deben considerarse complementarios, ya que cada uno aporta algo que permite, en definitiva, una medición más completa de la pobreza. 


\subsection{La pobreza en Chile}

\section{Algo de historia}

Uno de los primeros intentos de cuantificar la pobreza en Chile fue el de Ahumada (1958), quien estimó, en un trabajo relativamente avanzado para la época, que un 58,6\% de la población era pobre en $1955^{1}$. Para él, las necesidades básicas que debía satisfacer una familia tenían que ver primordialmente con la alimentación, educación y vivienda. En los setenta se desarrollaron diversos estudios de cobertura nacional, aplicando dos metodologías distintas: de las Necesidades Básicas Insatisfechas (NBI), y de la Canasta de Satisfacción de Necesidades Básicas (CSNB)

El primer estudio sobre la extrema pobreza basado en el método de NBI, y conocido como "el mapa de la extrema pobreza", fue realizado en 1974 conjuntamente por la Oficina de Planificación Nacional (ODEPLAN) y el Instituto de Economía de la Pontificia Universidad Católica de Chile. Este estudio, basado en información del Censo de 1970, consideró elementos tales como las características de la vivienda, los bienes durables de que disponían los hogares y el nivel de educación de sus miembros, concluyendo que la extrema pobreza afectaba al 21\% de la población. Posteriormente, Mujica y Rojas (1986) usaron datos del censo de 1982 para actualizar el mapa, obteniendo como resultado una caída de la extrema pobreza hasta el 14\% para dicho año. En la actualidad, los análisis basados en esta metodología son mediciones complementarias a la oficial.

El método de la construcción de una CSNB es el que hoy se usa en las mediciones oficiales de pobreza. Altimir (1979) fue quien aplicó esta metodología por primera vez en el país, obteniendo como resultado una cifra de $17 \%$ de pobreza y una tasa de indigencia de 6\% para 1970. Esto dio inicio a una serie de estudios en la década del ochenta que adoptaron este enfoque. Rodríguez (1985) calculó que la extrema pobreza alcanzaba al 30,3\% en 1983, mientras que Torche (1987) estimó que en 1985 la tasa de pobreza alcanzaba el $45 \%$ y que la de indigencia era de $25 \%$. Sin embargo, el contenido de la canasta básica difería bastante entre los investigadores.

En 1990, la CEPAL elaboró una nueva canasta que contenía los requerimientos calóricos mínimos para asegurar la subsistencia de las personas. Las autoridades del gobierno del Presidente Aylwin (1990-1994) se

\footnotetext{
${ }^{1}$ También los trabajos que estudian la distribución del ingreso en Chile datan de hace varias décadas, como Crocco (1950), que examina la distribución de rentas personales para 1948 y el texto de CEPAL (1954), que calcula la distribución del ingreso para 1942 y 1948.
} 
inclinaron por esta opción metodológica para realizar la medición oficial. Esto reconocía que en el sistema económico imperante en el país los bienes y servicios necesarios para satisfacer las necesidades personales se adquieren a través del mercado, por lo que comparar los ingresos con la canasta relevante refleja mejor las situaciones de pobreza e indigencia. La aplicación de esta metodología, vigente hasta hoy, entrega una línea de pobreza que se actualiza de acuerdo a la inflación. Los ingresos de los hogares se basan en la información que se obtiene de la Encuesta de Caracterización Social y Económica Nacional (CASEN).

\section{La Encuesta CASEN}

La Encuesta CASEN ${ }^{2}$ es, entonces, fuente fundamental de información para medir la pobreza en Chile. Por ello, es útil revisar brevemente sus contenidos y objetivos. La CASEN, realizada por Mideplan, es una encuesta de hogares representativa a nivel nacional, regional, urbano, rural y comunal, que cubre 335 comunas del país en la última versión de 2006.

Esta encuesta entrega información sobre las condiciones socioeconómicas del país, las características de la pobreza y la distribución y composición del ingreso de los hogares, así como antecedentes sobre los beneficiarios de los programas sociales, permitiendo identificar a los sectores que no acceden a dichos programas, y así calcular los déficit de atención asociados. Esta información es un antecedente básico para focalizar el gasto social y es utilizada por diversas instituciones multilaterales y especialistas técnicos para la investigación.

De acuerdo a Mideplan, la Encuesta CASEN se desarrolla para cumplir los siguientes objetivos generales:

- Conocer la situación de los hogares y de la población y de los grupos prioritarios para la política social, en una variedad de aspectos socioeconómicos.

- Evaluar la cobertura y la distribución del gasto de los programas sociales más importantes, así como el impacto de este gasto en el ingreso y su distribución.

- $\quad$ Medir la magnitud e incidencia de la pobreza, permitiendo caracterizar los hogares en situación de pobreza.

- $\quad$ Evaluar los programas sociales que están en desarrollo actualmente, y realizar las acciones que permitan que el gasto social llegue a los segmentos de la población identificados como prioritarios.

\footnotetext{
${ }^{2}$ Para más información sobre esta encuesta revisar www.mideplan.cl.
} 
- Caracterizar a la población por diversas variables, como nivel de ingreso de los hogares, condiciones habitacionales, educacionales, etc.

Justamente por las bondades de este instrumento, para un país del nivel de desarrollo de Chile no hay ninguna buena razón para que la encuesta no se realice anualmente y entregue así con mayor periodicidad una "radiografía" de nuestra situación de pobreza y distribución de ingresos. Tampoco es conveniente que Mideplan no dé a conocer al público rápidamente la encuesta completa, y que se tome varios meses analizándolas en solitario.

\section{La Encuesta de Presupuestos Familiares (EPF) y la Canasta de Satisfacción de Necesidades Básicas (CSNB)}

La metodología usada para la construcción de la CSNB vigente hoy en Chile se basa en análisis de la CEPAL de fines de los ochenta. Una gran ventaja de este método es que la canasta resultante toma en cuenta los hábitos de consumo efectivos de la población, es decir, se ajusta a las preferencias de los consumidores, evitando así que ésta resulte irreal y, probablemente, demasiado económica, como sería si la determinara la autoridad o el investigador. Por tanto, se requiere seleccionar un conjunto de satisfactores básicos a partir del consumo observado en la población.

El método se basa en determinar el costo de satisfacer las necesidades mínimas de las personas. En primer lugar, se requiere estimar el costo de satisfacer las necesidades nutricionales básicas, para lo cual se elabora una Canasta de Alimentos Básica (CAB), proceso que demanda gran cantidad de información — proporcionada fundamentalmente por la Encuesta de Presupuestos Familiares-y consta de múltiples etapas. Los productos escogidos para formar parte de la CAB son fruto de una selección consistente con el patrón de consumo observado en la población.

La estimación del costo de las necesidades no alimentarias se hace usando un coeficiente basado en la relación observada entre los gastos en alimentación y los gastos totales en consumo (conocido como el coeficiente de Engel) de los diferentes estratos de hogares; éste se multiplica por el valor de la CAB para obtener el costo total de la CSNB. Es decir, para las otras necesidades no se usa una canasta, como sí ocurre con las de alimentación. Esto obedece a consideraciones de orden práctico, puesto que en las áreas de educación, salud, vestuario, comunicación, transporte, vivienda, recreación, equipamiento del hogar, etc., no hay criterios normativos ni consensos similares a los existentes en materia nutricional. El supuesto im- 
plícito es que las necesidades alimentarias tienen mayor preeminencia en el gasto de las personas. Pese a los cuestionamientos que ha recibido este principio simplificador, los estudios indican que las familias más pobres dedican el grueso de sus ingresos a alimentarse, y que incrementan el gasto destinado al resto de sus necesidades a medida que aumenta su ingreso.

La IV EPF de 1987-1988 mostró que el tercer quintil era entonces el primero en tener suficiente ingreso para cubrir sus necesidades alimentarias. Para este quintil, su consumo total era 2,1 veces su gasto en alimentación, se multiplicó por 2 la CAB para obtener el valor de la CSNB, coeficiente que rige hasta el día de hoy.

\section{Las cifras de pobreza en Chile}

Una vez revisados los elementos básicos de la medición oficial de pobreza (e indigencia), conviene inspeccionar las cifras que ésta arroja. Las Figuras $N^{\circ} 1$ y 2 presentan las cifras oficiales para los últimos 20 años, desde 1987 a 2006. De acuerdo a ellas, los resultados de reducción de pobreza e indigencia en el país han sido muy exitosos.

Las razones de esta reducción son múltiples: el alto crecimiento económico y disminución del desempleo experimentado por la economía durante el período 1987-1997, un relativo estancamiento a fines de los noventa (que coincide con la recesión de 1999) y la posterior recuperación desde el año 2000, el crecimiento del gasto público social y los mayores niveles de escolaridad, entre otros factores. Que la pobreza y la indigencia se han reducido en

FIGURA N ${ }^{\circ}$ 1: $\quad$ POBREZA SEGÚN CANASTA OFICIAL BASE 1987-1988

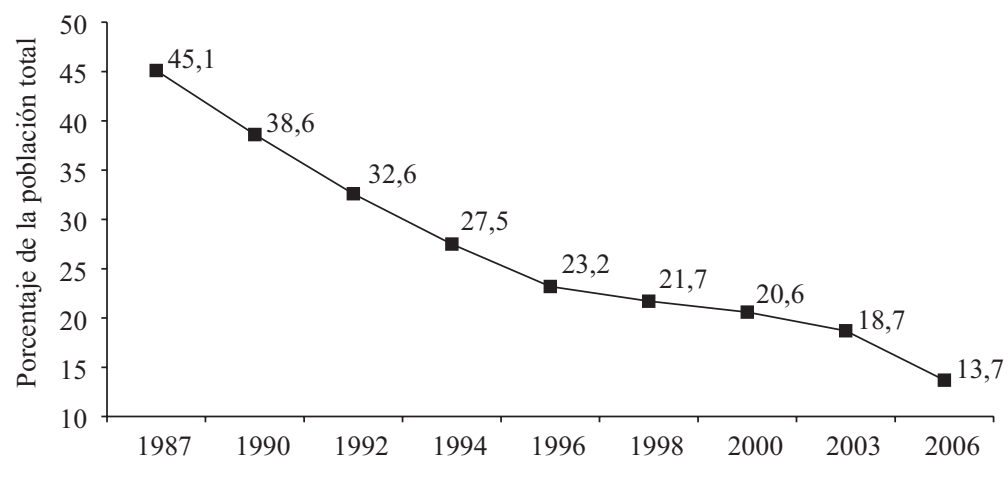


FIGURA No 2: $\quad$ INDIGENCIA SEGÚN CANASTA OFICIAL BASE 1987-1988

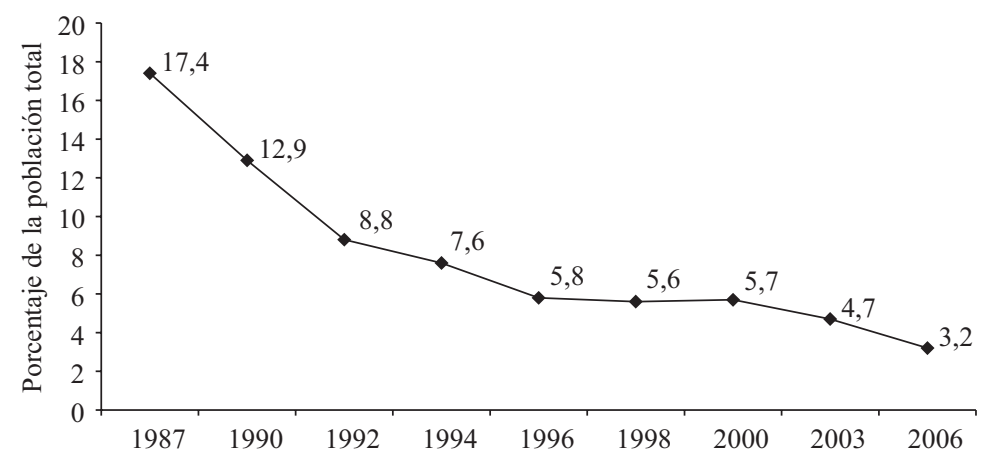

Chile durante los últimos 20 años es notorio y no es punto de debate. Sin embargo, cuando se considera una medida actualizada, las cifras oficiales de pobreza resultan demasiado optimistas y no corresponden a la realidad. En términos simples, la pobreza es mucho mayor que lo indicado por las cifras oficiales, ya que la línea de pobreza con la que ésta se ha calculado está obsoleta. La siguiente sección explica las razones de esta afirmación.

\section{EL DEBATE DE HOY: LA LÍNEA DE POBREZA ${ }^{3}$}

\section{1. ¿Por qué se debe actualizar la canasta?}

Los instrumentos utilizados para cuantificar una variable deben ser capaces de medir correctamente el objeto bajo estudio, entregar los mismos resultados en caso de que se decida replicar su metodología y discriminar correctamente. Si aplicamos estos criterios a la medición de pobreza, un instrumento adecuado debiera ser sensible ante la insuficiencia o suficiencia de ingreso para satisfacer las necesidades básicas de una familia, y clasificar correctamente a los hogares, es decir, no dejar hogares fuera de la pobreza cuando éstos son pobres ni considerar pobres a los que no lo sean.

Cuando se elaboró, la CSNB cumplió con estos criterios. Pero es inevitable que con el paso del tiempo cambie la realidad y también las variables sobre las cuales fue construida la canasta, por lo que un instrumento

${ }^{3}$ Las subsecciones 3.1 y 3.2 están basadas en Umbrales Sociales 2006: Una Propuesta para la Futura Política Social, elaborado por la Fundación para la Superación de la Pobreza (FSP) en 2005. 
que no se actualiza por un largo período, como ha ocurrido en Chile, deja de cumplir con los requisitos mencionados. Muchas de estas transformaciones han resultado en cambios definitivos. En esta sección se discuten al menos tres razones de peso para actualizar la canasta.

\section{- Cambian los satisfactores básicos}

Los satisfactores básicos son aquellos bienes y servicios que explican parte importante del gasto realizado por los hogares para satisfacer sus necesidades básicas, son consumidos por un número significativo de hogares y — frente a bienes sustitutos — son de menor costo.

Las necesidades básicas no varían (alimentación, salud, educación, vivienda, vestuario, etc.), pero sus satisfactores sí, lo cual se asocia en forma importante al momento histórico que vive un país. Por ejemplo, hace más de medio siglo muchos hogares consumían productos alimenticios cultivados por ellos mismos Desde entonces, los productos y precios han cambiado mucho en Chile y el mundo, y la forma en que se satisfacen las necesidades alimenticias también. Factores como las variaciones de edad, altura, peso, talla y actividad, y los procesos de urbanización, fecundidad, diversificación de productos, importaciones y rebajas arancelarias, han modificado los satisfactores y las cantidades con que los hogares resuelven sus necesidades. Así, la canasta del IPC elaborada con la IV EPF de 19871988 constaba de 368 artículos y 501 variedades; en cambio, la V EPF de 1996-1997 incluye 483 artículos y 1.195 variedades (canasta IPC 1998).

Es claro, entonces, que los satisfactores básicos no son estáticos en el tiempo y que su validez temporal es restringida. Por ello, diversos autores recomiendan actualizar la CSNB cada cierto tiempo, entre los que se puede mencionar a Citro y Michael (1995), Vaughan (2004) y Thorbecke (2004). De lo contrario, la evaluación respecto del ingreso necesario para adquirir la canasta básica pierde validez al hacer el análisis en base a productos que se dejaron de consumir y han sido sustituidos por otros de mejor calidad y distinto valor. Ejemplo de lo anterior es el aceite suelto, presente en la canasta de 1989, y que ha sido sustituido por el aceite embotellado.

- Cambia la estructura del consumo

La porción del presupuesto familiar que se usa para satisfacer las distintas necesidades básicas ha sufrido también importantes cambios en las últimas dos décadas. Esto se debe a fenómenos tales como el aumento del ingreso; los cambios en los estilos de vida; la forma en que se han ido 
estructurando las ciudades; los mayores costos de educación, salud y vivienda; el mayor gasto requerido para transportarse debido a las mayores distancias que separan el hogar del lugar de trabajo, entre otros.

Estos cambios han disminuido la proporción del gasto que se destina a alimentación; su contrapartida es un aumento significativo en la proporción que va a otros bienes y servicios básicos (vestuario, vivienda, transporte, salud, entre otras). Así, mientras los datos de la IV EPF daban cuenta de una relación entre el gasto total y el gasto en alimentación de 3,0 en promedio para los hogares de Santiago, dicha cifra se elevó al 3,6 en la V EPF. Esto tiene importantes consecuencias al momento de construir la CSNB, puesto que de este valor dependerá la estimación del coeficiente o factor por el cual se multiplica la CAB, como ocurre en la medición oficial de la pobreza en nuestro país.

- Se ajustan las recomendaciones nutricionales FAO-OMS-ONU:

La construcción de la CSNB oficial se elaboró de acuerdo a las recomendaciones nutricionales de la FAO-OMS-ONU propuestas en 1985. Éstas se ajustaron considerando el grado de urbanización y nivel de actividad física de la población chilena. No obstante, investigaciones recientes —entre las que destacan Costa-Font y Gil (2005), Flegal et al. (2005) y Popkin (2004) - han revelado un aumento del sedentarismo, que incide en las sugerencias nutricionales.

El grupo consultivo FAO-OMS-ONU propuso en 2001 varios cambios a las recomendaciones nutricionales para Chile. Se realizaron nuevos cálculos sobre requerimientos de energía para infantes, niños, adolescentes y adultos, basados en la evidencia reciente y corrigiendo los informes previos.

Además, se clasificaron los niveles de actividad física basados en el grado habitual de actividad consistente con una vida saludable, surgiendo recomendaciones respecto al gasto de energía y niveles de actividad física necesarios para mantener buena salud y reducir los riesgos de obesidad y otras enfermedades asociadas al sedentarismo. A su vez, se revisaron los estimadores de las necesidades de energía para embarazadas y lactantes.

Las nuevas recomendaciones y sus consecuencias, analizadas en Medina (2004), contemplan:

Infantes (hasta 1 año de vida). En relación a 1985, los requerimientos propuestos disminuyen en $12 \%$ para los 3 primeros meses de vida. Entre 
tres y nueve meses, se reducen en $17 \%$ y para las edades de nueve a doce meses se sugiere un $20 \%$ menos. Los requerimientos de los lactantes son $17 \%, 20 \%$ y $22 \%$ menos para las edades de 0 a tres, de tres a seis y de seis a nueve meses, respectivamente.

Niños y adolescentes. Respecto de 1985, los requerimientos propuestos son: $18 \%$ menores para los niños y $20 \%$ menores para las niñas cuando la edad sea inferior a los siete años; entre $12 \%$ y $15 \%$ menores para los niños y niñas entre siete y diez años, respectivamente; y $12 \%$ superiores para ambos sexos entre los doce y dieciocho años.

Adultos. Nuevas estimaciones de la tasa de metabolismo basal generaron un menor error de predicción y redujeron los sesgos de sobreestimación en hombres. Los requerimientos se ajustaron al incremento de peso en hombres y mujeres, y a la reducción en la actividad física. El efecto final fue reducir los requerimientos totales de energía.

\section{2. ¿Por qué la reticencia a actualizar la canasta?}

Los gobiernos suelen ser muy reacios a actualizar sus indicadores de pobreza, puesto que los instrumentos con los que ésta se mide son sensibles a las variaciones en los ingresos y gastos. Un período de desarrollo sostenido que aumente el empleo, los salarios reales y el ingreso por habitante tendrá consecuencias directas en la estructura de consumo de los habitantes. No parece razonable, en todo caso, modificar la línea de pobreza ante fluctuaciones transitorias del ingreso. Así, no se debería revisar al alza la línea en una corta expansión, ni tampoco bajarla cuando el país entra en recesión. En Chile este proceso no ha tenido un carácter meramente circunstancial, lo que se puede apreciar al analizar la evolución del PIB per cápita en los últimos 20 años en la Figura № 3. Desde 1987/1988, fecha en que se realizó la IV EPF, hasta 2006, el PIB per cápita se ha más que duplicado en pesos reales. Este incremento ha sido sostenido, aun considerando los efectos negativos de la recesión de 1999 sobre el crecimiento de la economía.

No obstante, el PIB puede presentar algunas falencias como indicador de bienestar material, al incluir la remuneración a la inversión extranjera y no considerar los efectos de variaciones de los términos de intercambio (que en Chile están dadas principalmente por los cambios en los precios del cobre y del petróleo). Una medida que da cuenta de estos efectos es el 
FIGURA N ${ }^{\circ}$ 3: $\quad$ PIB PER CÁPITA (BASE 1986=100)

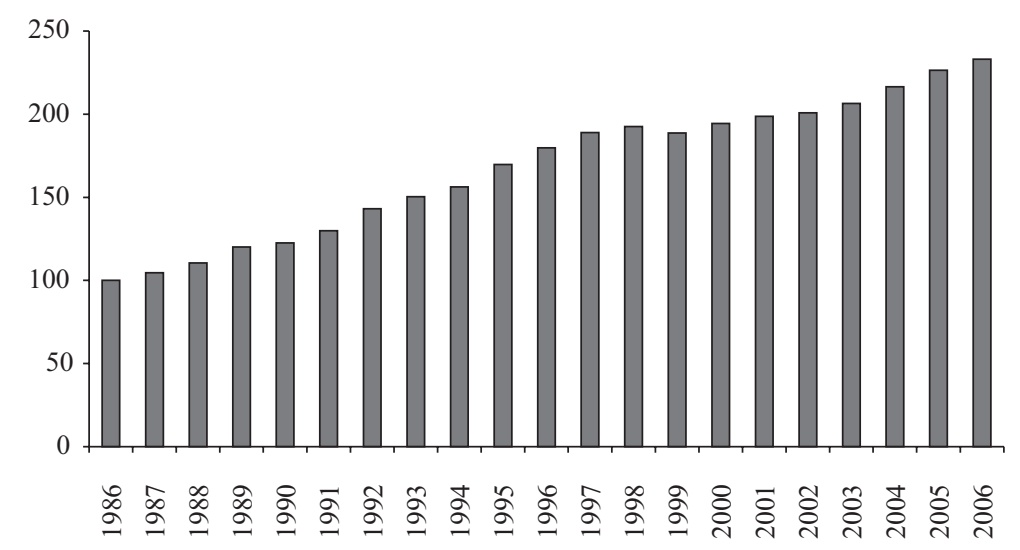

FIGURA No 4: $\quad$ INGRESO NACIONAL BRUTO DISPONIBLE PER CÁPITA (BASE 1986=100)

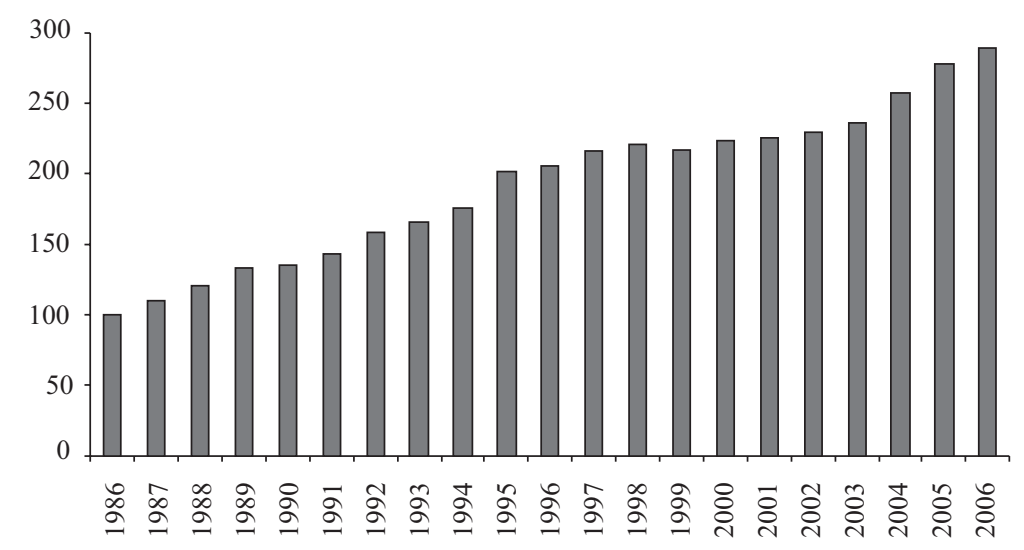

Ingreso Nacional Bruto Disponible per cápita, que se presenta en la Figura $\mathrm{N}^{\circ} 4$ para los últimos 20 años. Como se puede observar, el efecto sobre el ingreso de los chilenos es aún más notorio bajo esta medida, llegando casi a triplicarse durante dicho período. Por ello, el patrón de consumo actual de los chilenos no puede ser considerado circunstancial, lo que tiene claras consecuencias. Por ejemplo, es muy probable que si se construye la CSNB 
en base a los patrones de consumo que prevalecían en la década de los cincuenta, los resultados de una eventual medición 2006, arrojarían, erróneamente, que la pobreza ha sido prácticamente erradicada, lo que es simplemente producto de manejar un instrumento obsoleto. En definitiva, mientras más antiguo el instrumento, más probable es subestimar la pobreza, lo que equivale a una percepción demasiado optimista de la situación real.

Otro punto a considerar dice relación con la comparabilidad de las series. Cuando se actualiza la línea de pobreza, los nuevos datos no pueden ser contrastados directamente con mediciones anteriores. Este hecho ha sido usado recientemente como excusa para no actualizar la CSNB, aun cuando se dispone de información para ello de la V EPF, y pese al compromiso explícito de hacerlo por parte de Mideplan en $1999^{4}$. Sin embargo, para paliar este problema existen conocidas opciones como empalmar las series o aplicar el nuevo indicador de pobreza "hacia atrás". Pero incluso aunque no se realizara ninguno de estos ajustes, la actualización sirve para comprender mejor la realidad de la pobreza. Considérese, además, que tanto la canasta del IPC (que se elabora con la misma EPF), la ficha CAS (que fue reemplazada en 2006) y las cuentas nacionales han sido actualizadas (esta última dos veces) en las últimas dos décadas. Por tanto, las razones para no actualizar la canasta no resisten el más tímido de los cuestionamientos.

En Chile nunca se ha modificado la composición de la canasta oficial. Por ello, el cambio de método desde NBI a CSNB, efectuado en 1990, nos puede dar alguna pista de las consecuencias de realizar cambios de este tipo. A fines de los ochenta, el método de NBI — que usa indicadores de tipo patrimonial - entregaba una incidencia de pobreza bastante baja, pese a que un número considerable de chilenos sufrían aún de serias limitaciones de ingreso. Sin embargo, cuando la medición oficial aplicó el método de la CSNB, la pobreza subió a un $45 \%$ de la población. Por ello, una vez que asumió el primer gobierno de la Concertación, se aumentó significativamente el gasto social, incrementando la recaudación fiscal para financiarlo.

El cambio en la forma de medir la pobreza hizo visible a aquella importante parte de la población cuyos ingresos fueron golpeados más intensamente por las crisis de 1982-1983. Por lo tanto, un mejor instrumento de medición favorece precisamente a quienes más lo necesitan, ya que permite a las autoridades tener una mejor aproximación a la realidad.

Desde entonces, la situación institucional ha cambiado mucho, permitiendo un incremento del gasto social dentro de un marco de responsabilidad fiscal y crecimiento económico. Además, el Estado ha ido reforzando

${ }^{4}$ Véanse las declaraciones públicas del Subsecretario de la época, Antonio Lara (El Mercurio, 20-VI-1999). 
consistentemente su acción en el ámbito social, creando instituciones especializadas y programas de desarrollo dedicados a estos temas. Sin embargo, el punto de fondo ayer y hoy sigue siendo el mismo. Ante el espejismo de una sociedad que tiene muy buenos indicadores de pobreza, el Estado puede sentir que tiene menos trabajo que hacer en asegurar un bienestar mínimo a la población y que puede dar prioridad a otros objetivos. Esto va en directo perjuicio de los pobres a los que el gobierno - por un error de medición- no considera como tales.

\subsection{Algunas experiencias internacionales en la actualización de líneas de pobreza}

La experiencia internacional demuestra que es un proceso natural el que los países intenten mejorar sus mediciones de pobreza. En esta subsección se revisan brevemente algunas experiencias de otros países que han actualizado sus líneas de pobreza, tal como lo indican los trabajos de Asra y Santos-Francisco (2001) y Kakwani (2003).

El caso de Indonesia resulta de particular interés, ya que tiene varios rasgos similares a la propuesta de actualización de este trabajo. En ese país, al igual que en Chile, se usa el método de la CSNB. Para calcular la canasta alimentaria se supone un requerimiento mínimo diario de 2.100 calorías per cápita. Antes de 1993, para traducir los requerimientos nutricionales a rupias se realizaba una interpolación lineal dado el gasto total y la correspondiente ingesta de calorías por grupo de gasto, separadamente para las zonas rurales y urbanas. Desde 1993, se define una canasta de bienes alimenticios que cumpla el requisito calórico para cada provincia usando el patrón de consumo de un grupo pobre de referencia, y luego, a través del gasto per cápita promedio mensual en los ítems de la canasta se calcula la línea de pobreza alimentaria. Además, la canasta de bienes es única para cada provincia. Por otro lado, las canastas se actualizan para considerar los cambios en los patrones de consumo de la población, tal como se planteó aquí al exponer las razones para actualizar la canasta en Chile. Otra mejora importante ocurrida a partir de 1993 fue el uso de encuestas adicionales para determinar la canasta de bienes no alimentarios, en vez de aplicar un factor. Nuevamente, esta canasta difiere de una provincia a otra. Luego, ésta se costea en forma similar a la alimentaria, y se suman para obtener la línea de pobreza total.

Tailandia también usa el método de la CSNB y ha hecho esfuerzos por mejorar sus medidas de pobreza. En este caso hay dos mejoras importantes a partir de 1992. La primera es que se construyen distintas canastas 
alimentarias entre regiones, para considerar las diferencias en cuanto a necesidades calóricas, las que se costean considerando las diferencias en el costo de vida entre las regiones. Luego, para obtener la línea de pobreza total se supuso inicialmente que las familias pobres gastan un $60 \%$ de su presupuesto total en alimentación, permitiendo así obtener el componente no alimentario y, por lo tanto, la línea de pobreza total. Sin embargo, para tomar en cuenta las diferencias en precios relativos entre los bienes alimentarios y los no alimentarios, esta razón se actualiza anualmente, en forma separada para cada área y región, usando los índices de precios regionales para los bienes alimentarios y no alimentarios.

En India, la línea de pobreza oficial data desde 1979 y se basa en el método de consumo calórico. Inicialmente se estableció una línea de pobreza equivalente a un nivel de gasto per cápita mensual de 56,64 rupias, que permitía satisfacer un requerimiento de 2.435 calorías en el caso de zonas urbanas, y de 49,09 rupias para satisfacer un requerimiento de 2.095 calorías en el caso de las zonas rurales. Estas cifras están a precios base de 19731974, ya que las líneas fueron calculadas de acuerdo a una canasta de consumo construida con datos de una encuesta nacional aplicada entre esos años. Sin embargo, dado el tamaño y diversidad de las diferentes regiones en el país, la existencia de una línea única para toda el área urbana y otra para toda el área rural generaba serias distorsiones puesto que no se capturaban las diferencias regionales en el costo de la vida. Para enfrentar esta deficiencia, en 1993 se decidió crear líneas de pobreza específicas por estado. Para ello, se estimaron índices de precios que pudieran medir las diferencias en el costo de la vida a través de los estados. Para la India rural se tomó como base la línea de pobreza ya mencionada a precios de 19731974, y usando los índices de costo de la vida de cada estado, se computó la línea de pobreza para cada uno de ellos. Para la India urbana se realizó un ejercicio similar. Bajo este procedimiento es posible comparar el fenómeno de la pobreza entre estados.

Incluso China ha realizado ajustes a la forma en que calcula la pobreza. En este caso, no obstante, esas mejoras corresponden fundamentalmente a la línea de pobreza rural, ya que no se ha establecido un estándar para determinar la pobreza urbana, la cual ha empezado a incluirse recientemente en la agenda de las autoridades, en vista de los cambios sociales y demográficos que está experimentando el país. En China, la necesidad de cuantificar el fenómeno de la pobreza dice relación principalmente con la necesidad de definir criterios para asignar fondos para aliviarla. En 1986, el gobierno lanzó un plan masivo de reducción de la pobreza, por lo que se requería identificar a las regiones más pobres para definir a los beneficiarios. La línea 
de pobreza rural oficial fue fijada en 150 yuanes anuales, aunque en ciertas regiones consideradas especiales este valor se elevó a 200 o 300 yuanes anuales. En 1993, se hicieron esfuerzos para cuantificar de manera más precisa la línea de pobreza, de modo que ésta no fuera fijada en forma tan arbitraria. El costo de la canasta alimentaria correspondía al valor de la canasta que cumpliera con el requisito de 2.100 calorías per cápita diarias y que reflejara los patrones de consumo reales. También se consideró una fracción de bienes no alimentarios, estableciendo que el componente alimentario representaba alrededor de un $60 \%$ de la línea de pobreza. Años más tarde se perfeccionó el proceso, usando un modelo de regresión para estimar los gastos no alimentarios de las familias. Además, la línea de pobreza se estima todos los años en que la Encuesta Familiar Rural (de donde se extrae la información necesaria) está disponible.

\section{ACTUALIZANDO LA CANASTA}

En la sección anterior se analizaron una serie de razones por las que es imprescindible actualizar la canasta. A continuación, se presenta una metodología para actualizar la CSNB que se basa en el trabajo desarrollado por la Fundación para la Superación de la Pobreza (FSP) entre los años 2001 y $2003^{5}$. En este trabajo participaron investigadores del Departamento de Nutrición de la Universidad de Chile, además de técnicos y estadísticos sociales con vasta experiencia en análisis de precios y manejo de la EPF y de la Encuesta CASEN ${ }^{6}$.

Cabe señalar que la actualización elaborada por la FSP ha seguido gran parte del camino metodológico que la CEPAL inauguró a comienzos de la década pasada y que dio origen a la canasta que actualmente se usa en la medición oficial de pobreza en el país. Sin embargo, se introdujeron algunos cambios a dicha metodología, que obedecen a nuevos acuerdos técnicos suscritos en el marco del equipo investigador de la FSP. Indudablemente, éstos producen resultados diferentes a los que se obtendrían aplicando íntegramente la metodología original.

${ }^{5}$ La medición de la sección 5 se basa en Umbrales Sociales... (2005) de la Fundación para la Superación de la Pobreza, por lo que las secciones 4.1 y 4.2 están fuertemente influidas por ese trabajo.

${ }^{6}$ La actualización de la CSNB fue fruto del trabajo de múltiples profesionales, entre los cuales están: Ernestina Pérez a cargo del análisis de precios de la V EPF, quien inició su trabajo en el proyecto como Jefa del Depto. de Precios del INE y actualmente se desempeña en CEPAL; Anna Christina Pinheiros, Carmen Arteaga y Margarita Fernández (nutricionistas), y Marcia Erazo (enfermera), quienes estuvieron a cargo del análisis nutricional. 
En ese sentido, es importante recordar que la CSNB es un instrumento que surge de las posibilidades de su época. En un intento por cuantificar la pobreza, los investigadores de CEPAL forzaron un diálogo entre la teoría y la práctica. Así, de un concepto de pobreza que nace al alero de una rica teoría de las necesidades humanas, los expertos terminaron dando forma a un instrumento de medición con marcado énfasis biológico (nutricional) y que utiliza un solo tipo de indicador (ingreso per cápita del hogar). Como se explicó en la sección 2, por sus características se le ha rotulado como método indirecto de medición, ya que facilita la detección de hogares que no disponen del "medio" (ingreso) para adquirir satisfactores (otro medio) que permita la resolución adecuada de sus necesidades básicas. No evalúa si éstas son realmente satisfechas; por tanto, ausculta consumo potencial.

Es una alternativa de medición de la pobreza que reduce mucha de la complejidad inherente a su concepto. Esto debe tenerse siempre presente. No obstante, a su favor está la gran practicidad y simpleza de su aplicación. Posee una importante capacidad sintética, es confiable, precisa y sus resultados son interpretables por el público no experto. Por último, es posible afirmar que su construcción es mucho más compleja y menos intuitiva de lo que habitualmente se piensa (Altimir, 1979).

También debe advertirse que algunas de las restricciones técnicas e informacionales de antaño —que limitaron las opciones metodológicas a la hora de construir la CSNB - se han tendido a resolver con el tiempo. Por tanto, resultaría altamente inadecuado actualizar la CSNB sin considerar el avance de la discusión metodológica, las estadísticas sociales y la experiencia acumulada tras casi veinte años de aplicación de este método en la región.

Si bien el análisis de la FSP no pudo absorber todas estas "novedades", al menos originó varias alternativas de canasta, a partir de la aplicación de criterios alternativos de selección de los productos que la componen. De ellas, este trabajo recoge una alternativa a partir de la cual se estiman la pobreza e indigencia para los años 2000 a 2006.

Como se explicó, la estimación de la CSNB tiene dos componentes principales: una Canasta Básica de Alimentos (que entrega el costo de satisfacer las necesidades nutricionales) y un factor multiplicador que expande el gasto de la Canasta de Alimentos hasta que se presume satisfacción de las necesidades no alimentarias (educación, salud, vivienda, transporte y comunicaciones, recreación, bienes durables, vestuario, servicios básicos, etc.). Esto se hace emulando la estructura de consumo de un quintil de la población seleccionado especialmente para tales efectos (denominado "Estrato de Referencia”). 
A continuación se describe el proceso de construcción de la CAB y se propone una forma para estimar el costo de las necesidades no alimentarias.

\subsection{Canasta básica de alimentos}

Éste es el componente de la CSNB que conlleva una mayor complejidad y riqueza metodológica; habitualmente se le denomina también como "método biológico". Para seleccionar los productos que conforman la CAB se realiza un exhaustivo análisis del gasto en alimentos que efectúan los hogares —agrupados generalmente en quintiles ${ }^{7-}$; se determina la disponibilidad de nutrientes; se escoge el grupo poblacional que en promedio cumple primero con las recomendaciones nutricionales de OMS-FAO-ONU ${ }^{8}$; y a partir de todo el listado de productos alimentarios registrado en la V EPF, se realiza una selección de éstos a partir de criterios de frecuencia, costocaloría, incidencia en el gasto, aporte nutricional, etc.; finalmente se balancea y valida nutricionalmente la canasta, y se valoriza a precios de mercado.

\subsubsection{Disponibilidad nutricional de los hogares}

La disponibilidad de nutrientes en los hogares se basó en la Información de la V EPF ${ }^{9}$, realizada por el INE en 1996-1997. Ésta es la base de datos más completa y confiable que existe en el país sobre hábitos de consumo ${ }^{10}$ y disponibilidad de alimentos ${ }^{11}$.

${ }^{7}$ Si bien la CEPAL agrupó originalmente a la población en quintiles de ingreso, existen diversas formas de agrupar a la población. Una interesante muestra de ello se encuentra en los documentos del Programa de Mejoramiento de Encuestas de Condiciones de Vida (MECOVI).

${ }^{8}$ Este ejercicio alcanzó a utilizar las recomendaciones de 1985.

${ }^{9}$ Esta Encuesta se realiza cada 10 años, aproximadamente, y tiene por finalidad actualizar la canasta del IPC (que permite medir la inflación). Para más información, véase www.ine.cl.

${ }^{10}$ Si bien la CSNB es para todo el país, hasta la IV EPF la muestra sólo consideró hogares del Gran Santiago. La V EPF incluyó dos pequeñas muestras de hogares de las ciudades de Arica y Punta Arenas pero sin representación quintílica — por lo que no se incluyeron en el presente análisis. Así, la CSNB se encuentra sesgada por los patrones de consumo de la capital. Es interesante advertir que la VI EPF — que se encuentra en plena realización y que estará disponible en 2008 - considera muestras de capitales regionales. Ello contribuirá de sobremanera a actualizar la CSNB considerando la variabilidad regional.

${ }^{11}$ Es menester señalar que la Encuesta no registra ciertos aportes nutricionales provenientes, por ejemplo, de los Programas de Alimentación Complementaria (PAE y PNAC) que resultan ser una fuente de nutrientes muy importante para los hogares del $40 \%$ más pobre de la población. En consecuencia, es probable que la disponibilidad de alimentos se encuentre subestimada en las EPF. Esto es un interesante desafío metodológico que debe ser abordado en la próxima actualización que se haga de la CSNB luego que se entreguen las bases de datos de la VI EPF. 
Construcción de quintiles: Para la construcción de los quintiles, se escogió el ordenamiento ascendente de hogares, según el criterio de ingreso per cápita del hogar que considera alquiler imputado.

Base de precios: Para asignar los precios a ciertas cantidades de productos, se utilizó la información de la canasta IPC 1989 como fuente principal. Sin embargo, en dicha base no existía información suficiente para asignar precios a todos los productos alimentarios registrados en la encuesta. Así, la información de precios fue enriquecida con los datos de la canasta IPC $1998^{12}$ y algunas estimaciones propias (a partir de muestras específicas del INE). Todos los precios fueron llevados a moneda de enero de 1997, debido a que los datos de la V EPF se encuentran expresados así.

Para obtener una rigurosa estimación de disponibilidad nutricional se realizaron otros procedimientos adicionales. Entre ellos destaca:

Bienes genéricos: Se identificaron aquellos productos genéricos en su denominación, debido a que la base de la V EPF no identifica variedades específicas. Es el caso del "corte” en las carnes o envasado (por ejemplo, en caso de galletas dulces). En estas situaciones se procedió a elaborar una estructura más detallada, estableciendo bienes específicos. Para desagregar la ponderación de estos productos se estimaron coeficientes de ajuste a partir de los lugares de recolección de la información de precios por parte del INE. Alimentos como "carne de vacuno" contienen subproductos, cortes, tipos de carne cuya composición nutricional es distinta; por ejemplo, el aporte nutricional de la "posta rosada" es distinto al "guachalomo".

Quintilización de precios: Algunos productos genéricos poseen precios diferenciados según su lugar de venta (variaciones de calidad y/o marca que se ofrecen en el mercado debido al disímil poder adquisitivo de los hogares). Para no subestimar (caso de quintiles de menor ingreso) o sobreestimar (caso de los estratos de mayor ingreso) la disponibilidad de unidades físicas de alimentos, se procedió a quintilizar la información de precios de algunos productos, realizando correcciones en el valor promedio de algunos bienes. Para ello, se utilizó información externa provista por el INE, sobre el precio de las "variedades" disponibles.

De gasto a unidades físicas: Para analizar la disponibilidad nutricional de los hogares, agrupados en quintiles, se transformó el gasto mensual (expresado en pesos) a unidades físicas de producto (expresadas en gramos

${ }^{12}$ Que, de hecho, surge del análisis de la V EPF. 
y litros). Ello se hizo dividiendo el "gasto registrado" por el "precio asignado" a una determinada cantidad de producto (generalmente, el costo de 100 gramos o 1 litro).

Factor de aprovechamiento: Existen productos que no son aprovechados íntegramente, debido a que parte de su peso corresponde a huesos, envases, etc. Para determinar la cantidad neta de alimento consumida se calculó el porcentaje de pérdida que representa la porción no comestible de un producto alimenticio. Para ello, se utilizaron las tablas de aprovechamiento elaboradas por el Departamento de Nutrición de la Facultad de Medicina de la Universidad de Chile, las que contienen los porcentajes de pérdida para diversos tipos de alimentos.

Alimentos fuera del hogar: Resulta insoslayable determinar el aporte nutricional de estos alimentos. Para ello, se utilizaron como referencia las recetas alimenticias habituales para Chile, contenidas en Urteaga y Gaete (1997). A partir de dicha información, se analizó la composición de cada ingrediente relativo a 100 gramos de la mezcla.

De unidades físicas a nutrientes disponibles: Luego de estimar la disponibilidad de alimentos, expresados en gramos y/o litros, se procedió a transformar éstos en nutrientes. Para dicho cálculo, se utilizó una base de datos preexistente, tomada de investigaciones norteamericanas; esta información está sistematizada y adaptada por Jury, Urteaga y Taibo (1997), quienes presentan la composición química y el valor nutricional de los alimentos considerando 100 gramos de producto. Esta fase del estudio se apoyó en el programa computacional Sofnut versión 2005, de Sofmática Ltda., que permite el análisis de bases de datos alimentarios de gran magnitud. Además, permite conocer la composición química por 100 gramos de alimento y también evalúa las porciones recomendadas por la pirámide alimenticia chilena.

\subsubsection{Seleccionando el estrato de referencia}

Con los datos de disponibilidad nutricional por hogar y quintil se inició la segunda fase de la construcción de la Canasta Básica de Alimentos, que consiste en seleccionar el "estrato" que servirá como referente para seleccionar los productos que la componen. Para ello, fue necesario determinar qué quintil cumplía primero con las recomendaciones nutricionales de 
TABLA No 1

\begin{tabular}{|c|c|c|c|c|c|}
\hline \multicolumn{6}{|c|}{ Brechas nutricionales } \\
\hline \multirow[t]{2}{*}{ Nutrientes } & \multicolumn{5}{|c|}{ Brechas } \\
\hline & Quintil 1 & Quintil 2 & Quintil 3 & Quintil 4 & Quintil 5 \\
\hline Kcal. & $-196,5$ & 94,4 & 180,3 & 507,1 & $1.119,2$ \\
\hline Proteínas & 13,8 & 22,3 & 26,4 & 37 & 59,1 \\
\hline Vit A & 725,8 & 977,1 & 986,6 & $1.253,5$ & $1.738,0$ \\
\hline Vit E & 9,2 & 11,2 & 12,3 & 14,4 & 19,5 \\
\hline Tiamina & 0,9 & 1,0 & 1,2 & 1,6 & 2,1 \\
\hline Riboflavina & 0,1 & 0,2 & 0,2 & 0,5 & 0,9 \\
\hline Niacina & $-0,3$ & 1,7 & 1,8 & 4,2 & 9,5 \\
\hline Vit B6 & 0,0 & 0,3 & 0,3 & 0,6 & 1,1 \\
\hline Folatos & $-189,7$ & -165 & $-157,6$ & $-69,2$ & $-68,2$ \\
\hline Vit B12 & $-0,7$ & $-0,8$ & $-0,5$ & $-0,2$ & 0,4 \\
\hline Vita C & 50,6 & 67,7 & 80,7 & 96,7 & 151,5 \\
\hline Calcio & $-641,7$ & $-583,2$ & $-562,7$ & $-476,7$ & $-311,7$ \\
\hline Fósforo & $-102,8$ & 30,7 & 77,2 & 235,9 & 612,0 \\
\hline Magnesio & $-62,4$ & $-44,7$ & $-34,3$ & $-3,8$ & 79,6 \\
\hline Hierro & $-0,2$ & 2,1 & 2,4 & 4,2 & 7,8 \\
\hline Zinc & $-2,4$ & $-1,5$ & $-1,3$ & $-0,1$ & 2,9 \\
\hline Selenio & 15,0 & 21,6 & 24,8 & 33,7 & 59,5 \\
\hline Cobre & $-1,1$ & $-1,0$ & $-0,9$ & $-0,8$ & $-0,5$ \\
\hline Ac. Pantoténico & $-1,6$ & $-1,3$ & $-1,2$ & $-0,8$ & 0,3 \\
\hline
\end{tabular}

Fuente: FSP (2005).

la OMS-FAO-ONU (ordenados de menor a mayor ingreso). Tal determinación exige estimar las "brechas nutricionales", es decir, establecer las distancias (superávit o déficit) entre los requerimientos de nutrientes por quintil de ingresos y la disponibilidad de los mismos.

Escala de adulto equivalente: Los requerimientos nutricionales de los hogares y quintiles se obtienen a través de un procedimiento donde los miembros de un hogar son expresados en una unidad nutricional común denominada un adulto equivalente y que permite conocer en detalle sus requerimientos en ese plano. En esta oportunidad se crearon escalas diferentes para mujeres y hombres debido a las diferencias que se registran entre sexos respecto de sus necesidades de consumo de micronutrientes.

Ajuste por trabajo doméstico: Habitualmente, el servicio doméstico puertas afuera y/o por hora es excluido del análisis de requerimientos. Sin embargo, es común que estas trabajadoras(es) consuman alimentos en los hogares donde trabajan. Así, se decidió estimar la ingesta de alimentos por 
parte del servicio doméstico puertas afuera y expresar dicho consumo en adulto equivalente (al igual que el servicio doméstico puertas adentro ${ }^{13}$ ). Ese valor fue agregado al cálculo de adultos equivalentes del hogar.

Identificación del primer quintil que cumple con los requerimientos: La información sobre disponibilidad nutricional de los hogares se contrastó con los requerimientos de los mismos. La Tabla $\mathrm{N}^{\circ} 1$ presenta las brechas resultantes de tal comparación.

Reconociendo que todos los estratos presentan déficit en algún micronutriente ${ }^{14}$, se definió como estrato de referencia al segundo quintil de ingresos, por ser aquel que primero satisface sus requerimientos de macronutrientes y cuyo consumo de micronutrientes presenta déficit similares a quintiles de mayor ingreso.

\subsubsection{Selección de los productos de la Canasta Básica de Alimentos}

Criterios de selección: Entre 1996 y 1997, los hogares del segundo quintil de ingresos del Gran Santiago efectuaron gastos en 157 artículos alimentarios distintos. A partir de ese conjunto de productos se realizó la selección de los satisfactores básicos, tomando en cuenta los siguientes criterios: (i) incidencia en el gasto; (ii) frecuencia de consumo; (iii) menor costo/caloría; (iv) presencia anual (caso de frutas y verduras).

La FSP desarrolló tres estrategias de selección de productos alimentarios en base a estos criterios, estableciendo umbrales de selección alternativos. Ello originó tres canastas de alimentos. De todas ellas, este trabajo optó por la de menor costo, la denominada CAB-1.

Umbrales de selección: La CAB-1 utilizó los siguientes umbrales de selección: (i) primero, seleccionó todos los productos que representaban una incidencia promedio en el gasto de los hogares $\geq 0,5 \%$; (ii) luego, seleccionó aquellos productos que tuviesen además una frecuencia de consumo superior al 25\% de los hogares; (iii) tercero, escogió aquellos productos que siendo sustitutos tuviesen un costo-caloría menor.

\footnotetext{
${ }^{13}$ En los hogares donde existe servicio doméstico puertas adentro, se considera al trabajador como adulto equivalente pero su remuneración no es incluida como parte del ingreso del hogar donde trabaja.

${ }^{14}$ Esta situación obligó posteriormente a corregir las cantidades de algunos productos incorporados a la $\mathrm{CAB}$, por la vía del patrón de consumo observado en el estrato de referencia, de manera que se resguardara el equilibrio alimentario y se favoreciera el consumo de nutrientes críticos.
} 
Esta primera selección arrojó 44 productos básicos, con un aporte calórico de 1.903,17 kcal/persona y 56,8 gr de proteína. Con el objeto de adecuar la disponibilidad a las actuales recomendaciones de ingesta de micronutrientes, fueron agregados alimentos pertenecientes a los grupos de frutas y verduras, adoptando el criterio de participación en el gasto durante todos los meses del año. Esto posibilitó agregar a la propuesta 7 productos, por lo que la canasta final quedó con 51 productos.

Balance nutricional de la canasta: Se realizaron ajustes y correcciones en las cantidades de los 51 productos seleccionados de modo que su aporte diario de micro y macronutrientes fuera consistente con una dieta balanceada, sin que por ello se desnaturalizaran los hábitos de consumo del estrato de referencia. Para ello, se utilizaron como marco de referencia las recomendaciones derivadas de la pirámide alimenticia FAO-OMS-ONU 2001. Así, se obtuvo una CAB con un aporte de 2.362 kcal por persona al día.

Oferta de alimentos: Por último, se analizó si el país tenía una oferta de alimentos suficiente como para satisfacer la demanda derivada de los productos que componen la CAB-1. Se trabajó con la información correspondiente a los años 1996 y 2000 tanto de ODEPA como de la FAO. Según ambas estimaciones, Chile posee el stock suficiente para satisfacer las necesidades alimenticias de la CAB.

TABLA N ${ }^{\circ} 2$

\begin{tabular}{|c|c|c|c|c|c|}
\hline \multicolumn{6}{|c|}{ CAB-1 } \\
\hline & COD & Alimento & Consumo (gr) & $\mathrm{Cal} /$ cant & Precio/cant \\
\hline & Cereales & & 332,1 & & \\
\hline 1 & v11110 & Pan & 235,3 & 644,8 & 103,2 \\
\hline 2 & v11710 & Pastas & 25,9 & 96,2 & 16,3 \\
\hline 3 & v11220 & Galletas dulces & 2,2 & 10,0 & 4,8 \\
\hline 4 & v11241 & Torta & 25,0 & 84,8 & 33,1 \\
\hline 5 & v11410 & Arroz & 28,0 & 102,2 & 13,3 \\
\hline 6 & v11510 & Harina & 13,8 & 50,1 & 5,5 \\
\hline 7 & v11810 & Empanadas de carne & 2,1 & 6,2 & 4,9 \\
\hline & Carnes & & 91,3 & & \\
\hline 8 & v12112 & Asado de tira & 3,5 & 7,3 & 6,7 \\
\hline 9 & v12115 & Posta rosada & 26,8 & 34,0 & 55,4 \\
\hline 10 & v12116 & Osobuco & 3,5 & 6,1 & 4,8 \\
\hline 11 & v12117 & Carne molida (10\% mat. grasa) & 18,9 & 40,1 & 26,5 \\
\hline 12 & v12311 & Chuletas de cerdo & 2,5 & 6,4 & 5,6 \\
\hline 13 & v12411 & Pollo entero faenado & 13,5 & 29,0 & 12,5 \\
\hline
\end{tabular}




\begin{tabular}{|c|c|c|c|c|c|}
\hline 14 & v12412 & Pollo trozado - Pechuga y trutros & 11,9 & 20,5 & 17,6 \\
\hline 15 & v12612 & Longanizas & 2,2 & 9,4 & 4,6 \\
\hline 16 & v12613 & Jamón & 3,5 & 5,2 & 5,1 \\
\hline 17 & v12614 & Mortadela & 5,0 & 15,6 & 10,4 \\
\hline \multicolumn{3}{|c|}{ Pescados } & \multicolumn{2}{|l|}{30,0} & \\
\hline 18 & v13111 & Merluza fresca & 20,0 & 21,6 & 26,3 \\
\hline 19 & v13220 & Jurel & 10,0 & 10,8 & 2,7 \\
\hline \multicolumn{3}{|c|}{ Lácteos, huevos } & \multicolumn{2}{|l|}{152,5} & \\
\hline 20 & v14111 & Leche líquida 31\% mat. grasa & 55,0 & 31,9 & 18,2 \\
\hline 21 & v14112 & Leche líquida semidescremada & 15,8 & 7,1 & 5,6 \\
\hline 22 & v14130 & Leche en polvo & 46,0 & 229,1 & 84,8 \\
\hline 23 & v14211 & Queso gauda-mantecoso & 6,4 & 22,9 & 14,0 \\
\hline 24 & v14310 & Yogur batido con sabor & 15,9 & 14,3 & 12,6 \\
\hline \multirow[t]{2}{*}{25} & v14410 & Huevos & 13,5 & 20,1 & 11,1 \\
\hline & \multicolumn{2}{|l|}{ Aceites } & \multicolumn{2}{|l|}{21,2} & \\
\hline 26 & v15111 & Aceite vegetal mezcla & 15,0 & 132,6 & 10,6 \\
\hline \multirow[t]{2}{*}{27} & v15220 & Margarina & 6,2 & 39,0 & 7,0 \\
\hline & \multicolumn{2}{|l|}{ Frutas } & \multicolumn{2}{|l|}{89,5} & \\
\hline 28 & v16110 & Limón & 9,7 & 3,2 & 2,2 \\
\hline 29 & v16120 & Naranja & 13,3 & 6,1 & 3,3 \\
\hline 30 & v16130 & Manzana & 27,9 & 16,5 & 6,3 \\
\hline 31 & v16150 & Plátano & 19,3 & 17,8 & 4,8 \\
\hline 32 & v16160 & Palta & 5,3 & 8,5 & 3,5 \\
\hline \multirow[t]{2}{*}{33} & v16710 & Kiwi & 13,9 & 8,5 & 4,0 \\
\hline & \multicolumn{2}{|c|}{ Verduras, legumbres } & \multicolumn{2}{|l|}{240,6} & \\
\hline 34 & v17110 & Tomate & 43,0 & 9,0 & 13,5 \\
\hline 35 & v17120 & Lechuga & 8,4 & 1,1 & 4,1 \\
\hline 36 & v17180 & Zapallo & 11,1 & 4,2 & 5,8 \\
\hline 37 & v17330 & Cebolla & 60,0 & 22,8 & 12,8 \\
\hline 38 & V17340 & Zanahoria & 26,6 & 11,4 & 1,7 \\
\hline 39 & v17370 & Рapa & 48,8 & 39,5 & 15,8 \\
\hline 40 & V17410 & Poroto & 18,0 & 60,7 & 13,3 \\
\hline \multirow[t]{2}{*}{41} & V17430 & Lenteja & 24,8 & 83,8 & 11,7 \\
\hline & \multicolumn{2}{|l|}{ Azúcares } & \multicolumn{2}{|l|}{290,2} & \\
\hline 42 & v17610 & Salsa de tomate & 4,2 & 1,3 & 2,3 \\
\hline 43 & v18110 & Azúcar & 40,4 & 156,2 & 12,5 \\
\hline 44 & v18370 & Polvo para preparar jugo & 16,1 & 62,0 & 8,1 \\
\hline 45 & v18442 & Helado en caja & 15,6 & 12,5 & 4,6 \\
\hline 46 & v18510 & Sal & 14,1 & 0,1 & 0,1 \\
\hline \multirow[t]{2}{*}{47} & v19110 & Bebida gaseosa & 200,0 & 78,0 & 60,8 \\
\hline & \multicolumn{2}{|l|}{ Otros } & \multicolumn{2}{|l|}{67,4} & \\
\hline 48 & v19120 & Agua mineral & 11,2 & 0,1 & 0,1 \\
\hline 49 & v19210 & Vino & 6,9 & 5,0 & 7,7 \\
\hline 50 & v19410 & Cerveza & 26,8 & 11,0 & 10,9 \\
\hline \multirow[t]{2}{*}{51} & v19630 & Almuerzo y comida & 22,5 & 45,7 & 42,0 \\
\hline & & & \multicolumn{2}{|r|}{$2362 \mathrm{Kcal}$} & $\$ 775$ \\
\hline
\end{tabular}




\subsection{El costo de los satisfactores de las necesidades no alimentarias}

Ésta es la fase más críptica y más polémica de la construcción de la CSNB. Ello porque no existen criterios consensuados (como los nutricionales) que permitan establecer cuáles son los satisfactores de las necesidades no alimentarias, cuándo y/o cuánto se requiere de ellos y dónde se adquieren o debieran ser adquiridos (mercado o estado).

Hasta ahora, esto se ha resuelto con la estimación de un factor que computa el costo de las otras necesidades. Dada la forma en que es construido, su valor expresa la "relación" que existe entre el gasto en alimentos y el gasto total. Es un múltiplo que expande el valor de la CAB hasta recrear la relación entre gasto en alimentos y gasto total observado en el estrato de referencia pero a una escala menor, es decir, de consumos básicos ${ }^{15}$.

Este procedimiento ha recibido críticas por la renuncia que hace desde el punto de vista "normativo" y porque el factor es muy sensible al paso del tiempo y se desactualiza con facilidad. Frente a ello, la FSP decidió "abrir" el factor y seleccionó bienes y servicios básicos para el resto de las necesidades. Con esta propuesta, se ha querido destacar que la aplicación mecánica del factor actual (que significaría una elevación significativa del valor de la línea de pobreza) no parece ser una alternativa razonable, dado que el patrón de gasto registrado en 1996/1997 revela algunos consumos muy estacionales, de categorías exclusivas o elevado costo. Por ello, resulta necesario barajar otras posibilidades que expresen la noción de "lo básico" y que, a su vez, mantengan un respeto por los hábitos de consumo de la población ${ }^{16}$.

TABLA N ${ }^{\circ} 3$

Relación gasto total/gasto en alimentos

Hogares del Gran Santiago (1988-1997)

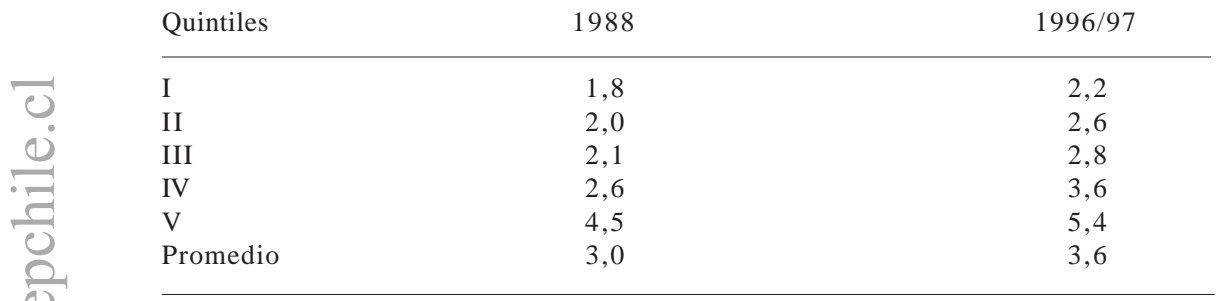

Fuente: FSP (2005) en base a VEPF, INE.

\footnotetext{
${ }^{15}$ FSP (2005).

${ }^{16}$ Ibídem.
} 
A continuación se resume la estrategia seguida al respecto por la FSP, que emula en parte el procedimiento de construcción de la Canasta Básica de Alimentos.

\subsubsection{Disponibilidad de bienes y servicios no alimentarios}

Análisis de gasto no alimentario: Se analizó el gasto en educación, salud, vivienda, vestuario, servicios básicos, bienes durables, cultura y recreación y otros de los hogares del segundo quintil de ingreso (estrato de referencia alimentario), con el propósito de mantener la estimación de los costos de las otras necesidades en el mismo estrato de referencia seleccionado para elaborar la CAB.

Base de precios: Para los bienes no alimentarios se construyó una base de precios que asigna un costo a ciertos bienes o servicios. Con este fin, se usaron métodos similares a los de la $\mathrm{CAB}$, sobre la base de los datos del IPC para 1989 y 1998.

Bienes: Para bienes genéricos, como por ejemplo "útiles escolares”, se elaboró una canasta compuesta por: cuaderno tamaño corriente y universitario, témpera y cartulina. Aquellos bienes para los que no hay seguimiento de precios se asimilaron a otros de similar naturaleza o reponderados.

Servicios: Los gastos de telefonía, agua y luz que consumen los hogares del segundo quintil, se transformaron así: (i) se seleccionó un mes de referencia; (ii) se estimó el gasto medio en cada servicio; (iii) se le restó el cargo fijo para el mes de referencia; (iv) se estimó la cantidad de unidades físicas consumidas en promedio por las familias.

De gasto en unidades físicas: Para transformar el gasto mensual de las familias a unidades de bienes y servicios se consideró el gasto efectuado por el hogar promedio del quintil y se dividió por el precio de cada bien o servicio.

Ritmo de adquisición de los bienes y servicios: Primero se estimaron las unidades físicas consumidas por las familias en el mes de referencia y luego se anualizó ese valor. Ello permitió clasificar los bienes y servicios en durables, semidurables y perecibles, con ritmos de adquisición aproximados mayor a 2 años, de año y medio, e inferior a 3 meses, respectivamente. 


\subsubsection{Selección de bienes y servicios básicos}

Para seleccionar los satisfactores básicos se consideraron su incidencia en el gasto, costo, exclusividad y generalidad.

Incidencia en el gasto: Se seleccionaron todos los productos y servicios que registraban una incidencia superior a $0,05 \%$ del gasto. Así, de un total de 307 bienes y servicios catastrados en la V EPF, 193 bienes y servicios quedaron seleccionados por incidencia y 2 se reincorporaron por su calidad de satisfactores básicos.

Selección por exclusividad, costo comparado o generalidad: Se excluyeron aquellos productos: (i) de elevado costo en relación a bienes similares y homologables (24 productos); (ii) exclusivos, de uso muy eventual (estacional) y baja frecuencia de consumo en el segundo quintil (44); (iii) genéricos, cuya denominación incluye gran variedad de bienes y servicios diversos sin seguimiento de precios (13); (iv) nocivos para la salud (sólo el tabaco). Así, la canasta no alimentaria quedó constituida por 113 bienes y servicios.

Estimación del costo: Se estimaron diversos costos para la canasta no alimentaria (sustitutos del factor multiplicador) tras aplicar criterios alternativos: (i) eliminación del gasto correspondiente a productos excluidos; (ii) reponderación del gasto de productos excluidos dentro de los incluidos que tuviesen una finalidad similar; (iii) adición de unidades físicas de productos excluidos a productos seleccionados de carácter sustituto, etc.

De las tres alternativas recién presentadas, los cálculos de pobreza que se presentan en el siguiente capítulo se realizaron en base COBS-2, dado que COBS-1 castiga demasiado el costo de los bienes y servicios no alimentarios al eliminar el gasto de los productos no seleccionados. COBS-2 y COBS-3 asumen que es necesario adquirir, por ejemplo, "más ropa” para satisfacer la necesidad, pero resguardan que sea a un valor menor. De ambas alternativas, se aplica la de menor costo. Esto lleva a un factor de 2,2 para amplificar el valor de la CAB. 
TABLA N ${ }^{\circ} 4$

\begin{tabular}{|c|c|c|c|c|}
\hline & COBS-1 & COBS-2 & COBS-3 & Factor \\
\hline Selectores & $\begin{array}{c}\text { Inc. } \geq 0,05 \\
\text { Exclusividad. } \\
\text { Costo comparado } \\
\text { nocivo }\end{array}$ & $\begin{array}{c}\text { Inc. } \geq 0,05 \\
\text { Exclusividad. } \\
\text { Costo comparado } \\
\text { nocivo }\end{array}$ & $\begin{array}{c}\text { Inc. } \geq 0,05 \\
\text { Exclusividad. } \\
\text { Costo comparado } \\
\text { nocivo }\end{array}$ & $\begin{array}{c}\text { Actualización } \\
\text { del factor } 2\end{array}$ \\
\hline $\begin{array}{l}\text { Tratamiento } \\
\text { de B\&S no } \\
\text { seleccionados }\end{array}$ & $\begin{array}{l}\text { Eliminación de } \\
\text { B\&S no } \\
\text { seleccionados }\end{array}$ & $\begin{array}{l}\text { Reponderación de } \\
\text { su gasto entre B\&S } \\
\text { seleccionados y de } \\
\text { finalidad similar }\end{array}$ & $\begin{array}{c}\text { Adiciona } \\
\text { unidades físicas } \\
\text { entre B\&S } \\
\text { seleccionados y } \\
\text { de finalidad similar }\end{array}$ & \\
\hline Cantidad de producto & $\begin{array}{ll}112 \\
112\end{array}$ & 112 & - & \\
\hline Valor diario & $\begin{array}{l}850(*) \\
978(*)\end{array}$ & $1037(*)$ & $1240(* *)$ & \\
\hline Equivalencia Factc & tor $2,1(* * *)$ & $2,26(* *)$ & $2,34(* *)$ & 2,6 \\
\hline
\end{tabular}

(*) A precios de noviembre de 1996.

(**) En relación al valor de $\mathrm{CAB}-1$.

Fuente: FSP (2005).

\section{LA POBREZA EN CHILE 2000-2006 CON UNA CANASTA ACTUALIZADA}

Esta sección presenta los resultados de pobreza e indigencia para Chile, estimados a partir de una Canasta de Satisfacción de Necesidades Básicas actualizada en base a los resultados de la V Encuesta de Presupuestos Familiares del INE (1996-1997). Adicionalmente, esta "puesta al día" incluyó algunas modificaciones metodológicas que la diferencian del procedimiento utilizado en 1990 por CEPAL al momento de construir la CSNB que rige hasta hoy.

Para obtener el valor de las líneas de pobreza e indigencia para 2000, 2003 y 2006, tanto a nivel urbano como rural, se efectuó un procedimiento similar al empleado por Mideplan: (i) como el valor de la Canasta de Alimentos Básica (CBA) estaba expresado a precios de noviembre de 1997, hubo que reajustar su costo a partir de la inflación acumulada de los productos considerados en ella; (ii) luego, se estimó el costo total de la CSNB según el 
procedimiento presentado en la sección anterior, que equivale a aplicar un factor de 2,2. Para estimar las líneas de pobreza e indigencia del mundo rural se aplicó sin modificaciones la estrategia vigente hasta el día de hoy; (iii) para computar el costo de la CAB de alimentos rural se aplicó un factor de 0,77 a la CBA urbana, y (iv) al valor resultante, se le aplicó un factor de 1,75 para obtener el valor de la canasta total.

El valor de estas 4 líneas para los años 2000, 2003 y 2006 fue de:

\begin{tabular}{|c|c|c|c|c|c|c|c|c|c|c|c|}
\hline \multicolumn{3}{|c|}{ TABLA $N^{\circ} 5:$} & \multicolumn{9}{|c|}{$\begin{array}{l}\text { DESAGREGADAS POR ZONA Y AÑO } \\
\text { (En moneda de noviembre de cada año) }\end{array}$} \\
\hline \multicolumn{4}{|c|}{$\begin{array}{l}\text { Valor de la CSNB - } \\
\text { actualizada (a) }\end{array}$} & \multicolumn{4}{|c|}{$\begin{array}{l}\text { Valor de la CSNB oficial - } \\
\text { Mideplan (b) }\end{array}$} & \multicolumn{4}{|c|}{$\begin{array}{l}\text { Diferencias entre ambas } \\
\text { CSNBs }(a-b)\end{array}$} \\
\hline & & Urbano & Rural & & & Urbano & Rural & & & Urbano & Rural \\
\hline \multirow[t]{2}{*}{2000} & LI & 28.019 & 21.575 & 2000 & LI & 20.281 & 15.616 & 2000 & LI & 7.738 & 5.959 \\
\hline & LP & 61.642 & 37.756 & & LP & 40.562 & 27.328 & & LP & 21.080 & 10.428 \\
\hline \multirow[t]{2}{*}{2003} & LI & 30.176 & 23.236 & 2003 & LI & 21.856 & 16.842 & 2003 & LI & 8.320 & 6.394 \\
\hline & LP & 66.388 & 40.663 & & LP & 43.712 & 29.473 & & LP & 22.676 & 11.190 \\
\hline \multirow[t]{2}{*}{2006} & LI & 32.500 & 25.025 & 2006 & LI & 23.549 & 18.146 & 2006 & LI & 8.951 & 6.879 \\
\hline & LP & 71.499 & 43.793 & & LP & 47.099 & 31.756 & & LP & 24.400 & 12.037 \\
\hline
\end{tabular}

Fuente: Elaboración propia en base al trabajo de la FSP (2005).

Como se puede apreciar, la CSNB actualizada es un 51\% más cara que la línea oficial de Mideplan. En consecuencia, para que en 2006 una persona sea considerada no pobre con las cifras actualizadas, debería disponer de al menos $\$ 813$ diarios por sobre el umbral del Ministerio en zonas urbanas, y $\$ 348$ en zonas rurales.

Para obtener los resultados de pobreza e indigencia, se estimó el ingreso mensual per cápita de todos los hogares a partir de las mismas tres fuentes de ingresos utilizadas por Mideplan para este efecto: (i) ingresos autónomos (provenientes del trabajo, las rentas y jubilaciones, entre otros); (ii) subsidios monetarios (correspondientes a todas las transferencias directas de dinero en efectivo desde el Estado al hogar, tales como SUF, PASIS, Bono de Protección, SAP, etc.); (iii) alquiler imputado a la vivienda propia, que se suma a los dos anteriores. Esta última fuente consiste en imputar un 
ingreso a todos los hogares que habitan su vivienda propia pagada y que equivale a un porcentaje del alquiler que, supuestamente, se les cobraría por vivir allí; este ingreso es importante en contextos de pobreza y vulnerabilidad debido a que muchos hogares residen en viviendas (sociales) cuya deuda ha sido condonada.

Los resultados de incidencia de la pobreza e indigencia para 2000, 2003 y 2006 aparecen en la Tabla $\mathrm{N}^{\circ} 6$.

Los datos muestran que durante el sexenio 2000-2006 la pobreza disminuyó de $36,6 \%$ a $29 \%$ de la población, y que prácticamente todo este progreso se dio entre 2003 y 2006. Otro tanto puede decirse sobre la indigencia, que se redujo de $10,4 \%$ a $6,2 \%$ de los chilenos en el mismo lapso. Esta tendencia también se manifiesta al aplicar la CSNB oficial. En consecuencia, se puede afirmar que tanto los resultados de Mideplan como los de este estudio son consistentes con la recuperación económica vivida por el país, la mayor disponibilidad de empleo — en especial a finales del período-, el desarrollo de políticas sociales activas y permanentes, como el aumento de subsidios directos e indirectos tras la puesta en marcha de programas como el Chile Solidario, los reajustes a las pensiones básicas, etc. que se registraron en este período.

Sin embargo, destaca también visiblemente la gran diferencia entre los niveles de pobreza medidos por Mideplan y las cifras que aporta este trabajo aplicando una CSNB actualizada. Así, para el año 2006 (que corresponde a la última aplicación de la CASEN), las mediciones arrojan 13,7\% y

TABLA N ${ }^{\circ}$ 6: $\quad$ INCIDENCIA COMPARADA POR SITUACIÓN DE POBREZA SEGÚN CSNBMIDEPLAN Y CSNB-ACTUALIZADA, DESAGREGADAS POR AÑO (Expresado como porcentaje de la población total)

\begin{tabular}{|c|c|c|c|c|c|c|c|c|c|c|c|}
\hline \multicolumn{4}{|c|}{$\begin{array}{l}\text { Incidencia por situación } \\
\text { de pobreza } \\
\text { CSNB - actualizada (a) }\end{array}$} & \multicolumn{4}{|c|}{$\begin{array}{l}\text { Incidencia por situación } \\
\text { de pobreza } \\
\text { CSNB - Mideplan (b) }\end{array}$} & \multicolumn{4}{|c|}{$\begin{array}{l}\text { Diferencia entre CSNB } \\
\text { expresado en Ptos \% } \\
\text { de población (a-b) }\end{array}$} \\
\hline & 2000 & 2003 & 2006 & & 2000 & 2003 & 2006 & & 2000 & 2003 & 2006 \\
\hline PI & 10,4 & 9,6 & 6,2 & PI & 5,6 & 4,7 & 3,2 & PI & 4,8 & 4,9 & 3 \\
\hline PNI & 26,2 & 26,8 & 22,8 & PNI & 14,6 & 14 & 10,5 & PNI & 11,6 & 12,8 & 12,3 \\
\hline $\mathrm{PT}$ & 36,6 & 36,4 & 29 & $\mathrm{PT}$ & 20,2 & 18,7 & 13,7 & $\mathrm{PT}$ & 16,4 & 17,7 & 15,3 \\
\hline NP & 63,4 & 63,6 & 71 & NP & 79,8 & 81,3 & 86,3 & NP & $-16,4$ & $-17,7$ & $-15,3$ \\
\hline
\end{tabular}

Nota: PI: pobres indigentes; PNI: pobres no indigentes; PT: pobreza total; NP: no pobres.

Fuente: Elaboración propia a partir de datos de las bases CASEN 2000, 2003, 2006. 
TABLA N ${ }^{\circ} 7: \quad$ INCIDENCIA DE LA POBREZA CON LÍNEA ACTUALIZADA MENOS \$3.000 (Expresado como porcentaje de la población total)

\begin{tabular}{lrrr}
\hline & 2000 & 2003 & 2006 \\
\hline Indigentes & 8,2 & 7,3 & 5,0 \\
Pobres no indigentes & 23,5 & 23,6 & 19,7 \\
Pobreza total & $\mathbf{3 1 , 7}$ & $\mathbf{3 1 , 0}$ & $\mathbf{2 4 , 7}$ \\
NP & 68,3 & 69,0 & 75,3 \\
\hline
\end{tabular}

Fuente: Elaboración propia a partir de base de datos CASEN 2000, 2003, 2006.

$29 \%$ de pobres, respectivamente; y 3,2 y 6,5\% de indigentes, respectivamente. Esto ocurre por dos cambios fundamentales en los patrones de consumo de los pobres (y la población en general) en la década que separa a la IV y V encuestas de presupuestos familiares. Primero, los pobres modificaron su consumo hacia productos más diversificados y de mejor calidad (por ejemplo, más frutas y verduras, aceite embotellado en vez de aceite suelto). Segundo, en 1997 los alimentos representaban una porción menor del gasto total de los pobres; ello hace que el factor de ajuste, en vez de ser 2 (como en la encuesta de 1987) sea de 2,2 usando la encuesta 1996-1997, lo que empuja más la línea de pobreza hacia arriba, a partir de la línea de indigencia. Nótese, sin embargo, que el factor 2,2 proviene de la alternativa de menor costo (que no elimina el gasto de los productos no seleccionados) en la Tabla $\mathrm{N}^{\circ} 4$; usar directamente la proporción del gasto no alimenticio sin correcciones llevaría a un factor 2,6, que subiría fuertemente la línea de pobreza.

Debe destacarse también que existe un gran número de personas y familias que se distancian de la línea de la pobreza oficial (en ambas direcciones) sólo por unos cuantos miles de pesos. Por ejemplo, si reducimos sólo en \$3.000 pesos la línea de pobreza actualizada para el año 2006, la incidencia de este fenómeno se reduciría en cerca de un 5\%; es decir, un ventil de población podría “salir de la pobreza”, como muestra la Tabla Nº 7.

\section{LIMITACIONES Y DESAFÍOS PENDIENTES}

Tras casi 20 años de aplicación, la medición de la pobreza a través de la CSNB ha sido objeto de diversas críticas conceptuales y técnicas. Los puntos en discusión han quedado suficientemente documentados en iniciativas como el Mecovi. A la luz de ellos, resulta importante dejar constancia de las limitaciones y desafíos del presente estudio. Esto adquiere especial relevancia en el momento actual, en que hay una fuerte discusión pública 
sobre la necesidad de actualizar la CSNB oficial. Estos desafíos y limitaciones deben ser abordados por las partes en discusión, reflexionados y resueltos.

\section{Reponer el carácter de indicador de la CSNB}

El indicador de pobreza medido por ingreso representa una aproximación indirecta al fenómeno de la precariedad socioeconómica. La pobreza es un fenómeno multifactorial en sus causas y multidimensional en sus manifestaciones. En ese contexto, la pobreza resulta una experiencia por momentos abstracta e intangible que es difícil de observar directamente a menos que se reduzca mucha de su complejidad.

El valor de la CSNB radica en entregar un indicador agregado de desarrollo social. Por ello, para focalizar las políticas sociales requiere ser complementado por otros instrumentos que ayuden a precisar y enriquecer la mirada (como la Ficha CAS, hoy de Protección Social). Sin embargo, resulta muy útil para determinar cuánto se ha avanzado en bienestar y desarrollo social.

Cabe recordar que esta medición fue impulsada por CEPAL en un contexto donde la comprensión y medición de la pobreza en los países era muy débil. Se trataba de un fenómeno difícil de cuantificar y precisar, ante lo cual no se tomaban las decisiones de política adecuadas. En ese contexto, los expertos de CEPAL impulsaron mediciones a partir de las bases de información disponibles, ya que era muy oneroso hacer encuestas sólo para medir pobreza, o bien no existía la voluntad política para ello.

Hoy es importante tener presente que la evolución de la pobreza por ingresos está lejos de responder exclusivamente a las políticas estatales y de subsidios, toda vez que los ingresos del trabajo son tremendamente relevantes y explicativos del ascenso y descenso a ella. Así, si bien la magnitud de la pobreza es habitualmente usada para evaluar políticamente la gestión social de un gobierno, la pregunta más adecuada que se puede derivar de este indicador es: ¿qué pasa en el país en que existen hogares con poderes adquisitivos tan limitados? La respuesta inmediata está en el empleo y su calidad. A su vez, la inserción de las personas en el mercado del trabajo responde a variables como las políticas educacionales, la legislación laboral, el lugar de residencia, el crecimiento del sector MIPYME, etc.

Por ello, es importante que las cifras sean objeto de reflexión. A futuro, se sugiere evitar fuertes saltos discretos en la medición (pobre v/s no pobre), en circunstancias que la pobreza es un fenómeno más o menos continuo. Esto es especialmente relevante en los países en desarrollo, que generalmente realizan sus mediciones de pobreza en base a líneas de valor muy bajo. 


\section{Establecer líneas de pobreza comparables en el tiempo}

En la práctica, una vez que se ha establecido la línea de pobreza en una determinada fecha, existen básicamente dos maneras de actualizarla con el paso del tiempo. La primera consiste en estimar una línea de pobreza para un año base y actualizarla de acuerdo a un índice de precios al consumidor. La segunda es construir una nueva línea de pobreza. La primera forma considera los cambios de precios, aunque mantiene la canasta de consumo asociada a la línea de pobreza en el año base. En principio, la ventaja de esta opción es que permite fácilmente realizar comparaciones consistentes de pobreza a través del tiempo. En cambio, bajo la segunda forma, se consideran tanto cambios de precios como modificaciones a la canasta de consumo. Como se explicó en este trabajo, el patrón de consumo de los habitantes de un país cambia en el tiempo por diversos factores, lo que cambia el valor de línea de pobreza. El punto clave aquí dice relación con el bienestar. Aunque es necesario reconocer dichos cambios en la estructura de consumo para obtener cuantificaciones más reales del fenómeno de la pobreza, es bastante probable que aunque la incidencia de dicho fenómeno se vea aumentada al contar con una línea de pobreza actualizada, todas las personas tengan, de hecho, un nivel de bienestar mayor. Por ende, bajo la segunda manera se dificulta realizar comparaciones de pobreza en el tiempo (los valores obtenidos con la canasta actualizada versus la antigua). Ello, porque las canastas miden niveles de bienestar diferentes, y como se dijo anteriormente ha servido como excusa por parte de la autoridad para no actualizar la línea de pobreza.

Sin embargo, estudios recientes intentan dar solución al problema de comparabilidad cuando se actualiza la canasta. Arndt y Simler (2005), por ejemplo, resuelven un problema de optimización para determinar la composición de la canasta que cumpla con el objetivo de lograr un comportamiento racional del agente, en particular, que satisfaga las condiciones de preferencias reveladas. En términos simples, el problema de optimización busca encontrar las cantidades que satisfagan las condiciones de preferencias reveladas y que preserven, en el mayor grado posible, la información contenida en las canastas originales. Abordar este punto es un enorme desafío para futuras investigaciones.

\section{Economías de escala}

Uno de los aspectos a considerar en una futura actualización de la CSNB es la estimación de economías de escala. Todo indica que esta co- 
rrección técnica no altera tanto la incidencia agregada de la pobreza. Su aporte es más bien precisar el perfil de la pobreza: un nuevo integrante de la familia tiende a reducir el gasto per cápita dado que el consumo de luz, agua y vivienda, por ejemplo, crece menos que proporcionalmente al aumento de personas en la familia. Deben, entonces, ajustarse los valores de referencia en función del número de miembros de la familia (y también de su edad y sexo).

Estos ajustes requieren un análisis más profundo de los hábitos de las familias. Es altamente probable que, en ese contexto, hogares unipersonales de adultos mayores que reciben una pensión asistencial de \$48.000 queden bajo la línea aplicando economías de escala, mientras que hogares de 7 miembros de los cuales 4 son niños con un per cápita \$ 45.000 queden sobre la línea.

En la actualidad, la línea de la pobreza se aplica a nivel per cápita; no obstante, su valor se computa a partir del patrón de gasto de un hogar promedio del estrato de referencia, es decir, 4,4 personas. Por tanto, su valor tiene implícita la economía de escala que se genera en ese hogar promedio. Ello no es estrictamente homologable a hogares más pequeños o más grandes.

\section{La CSNB en regiones}

Debe considerarse que el costo de satisfacer las necesidades básicas varía significativamente entre las regiones. Cabe destacar que la VI EPF incluye un muestreo para las capitales regionales. Esta información debiera ser analizada en el proceso de actualización de la CSNB oficial.

\section{La CSNB en el mundo rural}

Éste constituye uno de los aspectos más cuestionados en la actualidad, ya que la CSNB tiene un valor menor en las zonas rurales. Más precisamente, la CAB rural representa el 77\% del valor de la CAB urbana; y el factor de Engel aplicado a la CAB urbana (2) se reduce a 1,75 en los sectores rurales. Se estima, entonces, que en el campo se usan productos que no se transan en el mercado para satisfacer las necesidades básicas. De acuerdo a esta hipótesis, en el campo se utilizaría menos dinero para transporte, energía, suministro de agua, etc., que en la ciudad ${ }^{17}$. Sin embargo, esto ha cambiado mucho desde 1987-1988 a la fecha y las diferencias, lejos de profundizarse, han tendido a desaparecer progresivamente.

\footnotetext{
${ }^{17}$ FSP (2005).
} 
La dificultad de actualizar el factor rural radica en la insuficiencia de información para determinar la profundidad de estas transformaciones, ya que las EPF no consideran muestras rurales. Por lo tanto, esto constituye un aspecto muy interesante para ser abordado en un proceso de actualización de la CSNB oficial.

\section{Estimación del aporte de los programas sociales orientados a la satisfacción de necesidades básicas}

La EPF es una encuesta de gastos, y ciertamente representa una forma de acercamiento muy importante a las prácticas de consumo de los hogares. Sin embargo, el consumo es más amplio que el "gasto". Los programas de alimentación complementaria, por ejemplo, contribuyen a aumentar significativamente la disponibilidad de alimentos en los hogares más pobres y — dentro de ellos - para sus miembros más vulnerables. Otros programas relacionados con la entrega de becas, útiles, equipamiento, vestuario, transporte son de vital importancia en los hogares del 20\% al $40 \%$ más pobre. En consecuencia, constituye un desafío metodológico muy interesante rescatar estas prácticas de satisfacción de necesidades, que no pasan por el gasto de los hogares y que por lo tanto no aparecen en la EPF.

En esta dirección, podría pensarse en construir una imputación de ingreso a los hogares que obtienen estos aportes de modo tal que la medición de la pobreza determine mejor la capacidad de un hogar de resolver sus necesidades (independiente de si es a través de satisfactores de origen estatal o de mercado). No se trata de incluir los aportes de todo programa social, sino de aquellos que están vinculados con los ítems de consumo de la EPF y que constituyen transferencias específicas al hogar y sus miembros.

Este planteamiento lleva a replantear dos aspectos ligados a este método: (i) durante el proceso de construcción de la CSNB debe considerarse, por ejemplo, el aporte nutricional de los programas alimentarios para seleccionar al estrato de referencia; (ii) durante el proceso de medición de la pobreza, debe ser modificado el concepto de ingreso del hogar. Actualmente, éste se compone de ingresos autónomos, subsidios en dinero y alquiler imputado a la vivienda propia. Con esta propuesta, y siguiendo el mismo ejemplo, se podrían incluir otros ingresos adicionales provenientes de programas alimentarios. El problema radica en la selección de los programas que se considerarán ingreso del hogar y la manera cómo se construirá la imputación. Ésta es una importante dificultad práctica para aplicar esta idea. 


\section{Los costos de vivienda}

La EPF no estima adecuadamente el gasto en vivienda, ya que es considerado una inversión y no un gasto. Eso quiere decir que el gasto en satisfacer las necesidades de vivienda está subdimensionado en la CSNB. Esto debe ser corregido necesariamente en un proceso de actualización oficial, ya sea aplicando un factor o imputando un valor al quintil o estrato de referencia consistente con datos provenientes de la CASEN o del MINVU sobre los programas habitacionales, endeudamiento, etc.

\section{La pobreza transitoria y crónica}

Un tema emergente y muy relevante para el diseño de políticas sociales se relaciona con la aparición de la denominada pobreza transitoria y la fuerte reducción de la pobreza crónica. Estas categorías surgen del análisis longitudinal de la pobreza a partir del mismo instrumento (CSNB), pero esta vez monitoreando la trayectoria de los hogares. Resulta muy importante que la actualización de la CSNB no sirva sólo para el análisis de encuestas de corte transversal. El instrumento de medición de la pobreza adquiere su mayor novedad y aporte en estudios de panel o longitudinales que revelan los ascensos y descensos en torno a la línea y los vínculos de dichas trayectorias con nuevas y antiguas vulnerabilidades.

\section{La estimación de los ingresos por hogar y el ajuste por cuentas nacionales}

Para medir la pobreza, se requiere analizar los ingresos que declaran los hogares en la Encuesta CASEN. Antes de compararlos con las líneas de la pobreza, se realizan algunos ajustes comparando los volúmenes de ingreso declarados en la encuesta con las Cuentas Nacionales. Así, se aplican factores de corrección que buscan mitigar la subdeclaración y sobredeclaración. Este procedimiento es de gran importancia porque altera los ingresos de algunos hogares, particularmente aquellos con trabajadores por cuenta propia, y debe ser revisado por las consecuencias que acarrea para la estimación de la pobreza. En otros países (en especial desarrollados) la opción ha sido no ajustar. Es recomendable que las bases de datos de la CASEN sean entregadas con y sin los ajustes de modo que sea el investigador quien defina con qué ingresos va a estimar pobreza o calcular indicadores de distribución, entre otros. 


\section{REFERENCIAS}

Ahumada, J. (1958): En Vez de la Miseria. Santiago de Chile: Editorial Del Pacífico.

Altimir, O. (1979): "La Dimensión de la Pobreza en América Latina”. Santiago de Chile: Naciones Unidas, Cuadernos CEPAL.

Arndt, C. y K. Simler (2005): “Estimating Utility Consistent Poverty Lines”. Food Consumption and Nutrition Division, Discussion Paper 189. Washington, D.C.: International Food Policy Research Institute.

Asra, A. y V. Santos-Francisco (2001): “Poverty Line: Eight Countries’Experiences and the Issue of Specificity and Consistency”. ADB Poverty Forum. Manila: ADB.

Banco Mundial (1996): Poverty Reduction and the World Bank. Progress and Challenges in the 1990s. Washington D.C.

- (2001). Informe sobre Desarrollo Mundial 2000/2001: La Lucha contra la Pobreza. Nueva York: Oxford University Press.

CEPAL (1954): Antecedentes sobre el Desarrollo de la Economía Chilena, 19251952. Santiago de Chile: Editorial del Pacífico. (1990): "Una Estimación de la Magnitud de la Pobreza en Chile”. (2003): “Análisis de Resultados del Programa Puente”. División de Desarrollo Social.

(2007): Panorama Social de América Latina 2006. Santiago de Chile: Naciones Unidas.

Citro, C. y R. Michael (1995): Measuring Poverty: A New Approach. Washington D.C.: National Academy Press.

Costa-Font, J. y J. Gil (2005): "Obesity and the Incidence of Chronic Diseases: A Seemengly Unrelated Probit Approach”. En Economics and Human Biology, Vol. 3, $\mathrm{N}^{\circ} 2$.

Crocco, J. (1950): “Standard de Vida de la Población”. En CORFO: Geografía Económica de Chile, Tomo II. Santiago de Chile: CORFO.

FAO (2001): Human Energy Requeriments: Report of a Joint FAO/WHO/ONU Expert Consultation. Food and Nutritional Technical Series.

Feres, J. C. (1997): “Notas sobre la Medición de la Pobreza según el Método del Ingreso”. En Revista de la CEPAL, $\mathrm{N}^{\circ} 61$.

Flegal K., B. Graubard, D. Williamson y M. Gail (2005): "Excess Deaths Associated with Underweight, Overweight, and Obesity". En Journal of the American Medical Association, Vol. 293, № 15.

Fundación para la Superación de la Pobreza (FSP) (2005): Umbrales Sociales 2006: Una Propuesta para la Futura Política Social. Santiago de Chile: FSP.

INE (1989): IV Encuesta de Presupuestos Familiares, Diciembre 1987-Noviembre 1988. (2001): V Encuesta de Presupuestos Familiares, Junio 1996-Agosto 1997.

Jury G., C. Urteaga y M. Taibo (1997): Porciones de Intercambio y Composición Química de los Alimentos de la Pirámide Alimentaria Chilena. Santiago de Chile: Ed. LOM ediciones, $1^{\mathrm{a}}$ ed.

Kakwani, N. (2003): "Issues in Setting Absolute Poverty Lines”. Poverty and Social Development Papers No 3, June, Asian Development Bank, Manila.

Katz, M. y S. Molina (1974): “Mapa de la Extrema Pobreza en Chile”. ODEPLAN, Instituto de Economía Pontificia Universidad Católica de Chile. 
Medina, F. (2004): Determinación de los Requerimientos de Energía: Las Nuevas Recomendaciones. CEPAL, Reunión de Expertos sobre Nutrición, Desarrollo Humano y Pobreza. Washington D.C.: Naciones Unidas.

MIDEPLAN (1987-2003): Encuestas CASEN.

Mujica, R. y A. Rojas (1986): “Mapa de la Extrema Pobreza en Chile: 1982”. Instituto de Economía, Pontificia Universidad Católica de Chile.

Orshansky, M. (1963): “Children of the Poor”. En Social Security Bulletin, Vol. 26 , № 7.

Popkin, BM. (2004): "The Nutrition Transition: An Overview of World Patterns of Change”. En Nutrition Reviews, Vol. 62 No 7 pt 2, Supplement 1.

PNUD (1997): Informe de Desarrollo Humano. Nueva York: Oxford University Press.

Pradhan, M. y M. Ravallion (1997): "Measuring Poverty Using Qualitative Perceptions of Welfare”. Washington D.C.: Banco Mundial, Development Research Group.

Real Academia de la Lengua Española (2007). Disponible en www.rae.es

Rodríguez, J. (1985): La Distribución del Ingreso y Gasto Social en Chile. Santiago de Chile: ILADES.

Sen, A. (1984): Values, Resources and Development. Cambridge: Harvard University Press.

Thorbecke, E. (2004): “Conceptual and Measurement Issues in Poverty Analysis”. WIDER Discussion Paper 2004-004. Helsinki: WIDER.

Torche, A. (1987): “Distribuir el Ingreso para Satisfacer las Necesidades Básicas”. En F. Larraín (ed.), Desarrollo Económico en Democracia: Proposiciones para una Sociedad Libre y Solidaria. Ediciones Universidad Católica de Chile.

Urteaga, C. y C. Gaete (1997): Valor Nutricional de Preparaciones Culinarias Habituales en Chile. Medidas Caseras y su Equivalencia en Porciones de la Pirámide Alimentaria. Santiago de Chile: Edición Talleres Gráficos del Depto. de Evaluación, Medición y Registro Educacional.

Vaughan, D. (2004): "Exploring the Use of the Views of the Public to Set Income Poverty Thresholds and Adjust Them Over Time”. U.S. Census Bureau. 